\title{
Transcriptomic and metabolomic analysis of copper stress acclimation in Ectocarpus siliculosus highlights signaling and tolerance mechanisms in brown algae
}

Andrés Ritter ${ }^{1,2,3,5}$, Simon M Dittami ${ }^{1,2}$, Sophie Goulitquer ${ }^{4}$, Juan A Correa ${ }^{3}$, Catherine Boyen ${ }^{1,2}$, Philippe Potin ${ }^{1,2}$ and Thierry Tonon ${ }^{1,2^{*}}$

\begin{abstract}
Background: Brown algae are sessile macro-organisms of great ecological relevance in coastal ecosystems. They evolved independently from land plants and other multicellular lineages, and therefore hold several original ontogenic and metabolic features. Most brown algae grow along the coastal zone where they face frequent environmental changes, including exposure to toxic levels of heavy metals such as copper (Cu).

Results: We carried out large-scale transcriptomic and metabolomic analyses to decipher the short-term acclimation of the brown algal model E. siliculosus to Cu stress, and compared these data to results known for other abiotic stressors. This comparison demonstrates that $\mathrm{Cu}$ induces oxidative stress in $E$. siliculosus as illustrated by the transcriptomic overlap between $\mathrm{Cu}$ and $\mathrm{H}_{2} \mathrm{O}_{2}$ treatments. The common response to $\mathrm{Cu}$ and $\mathrm{H}_{2} \mathrm{O}_{2}$ consisted in the activation of the oxylipin and the repression of inositol signaling pathways, together with the regulation of genes coding for several transcription-associated proteins. Concomitantly, Cu stress specifically activated a set of genes coding for orthologs of ABC transporters, a $\mathrm{P}_{1 \mathrm{~B}}$-type ATPase, ROS detoxification systems such as a vanadium-dependent bromoperoxidase, and induced an increase of free fatty acid contents. Finally we observed, as a common abiotic stress mechanism, the activation of autophagic processes on one hand and the repression of genes involved in nitrogen assimilation on the other hand.

Conclusions: Comparisons with data from green plants indicate that some processes involved in $\mathrm{Cu}$ and oxidative stress response are conserved across these two distant lineages. At the same time the high number of yet uncharacterized brown alga-specific genes induced in response to copper stress underlines the potential to discover new components and molecular interactions unique to these organisms. Of particular interest for future research is the potential cross-talk between reactive oxygen species (ROS)-, myo-inositol-, and oxylipin signaling.
\end{abstract}

Keywords: Brown algae, Heavy metal, Copper stress response, Primary metabolism, ABC transporters, Oxylipins

\footnotetext{
* Correspondence: tonon@sb-roscoff.fr

'UPMC Univ Paris 06, UMR 8227, Integrative Biology of Marine Models, Station Biologique de Roscoff, Sorbonne Universités, CS 90074, F-29688 Roscoff cedex, France

${ }^{2}$ CNRS, UMR 8227, Integrative Biology of Marine Models, Station Biologique de Roscoff, CS 90074, F-29688 Roscoff cedex, France

Full list of author information is available at the end of the article
} 


\section{Background}

Brown algae (Kingdom Chromalveolata, Division Heterokontophyta, Class Phaeophyceae) are sessile macro-organisms of great ecological relevance in coastal ecosystems, and belong to an evolutionary lineage that has diverged from land plants and other multicellular organisms more than one billion years ago through secondary endosymbiosis [1]. Most of these seaweeds grow in the intertidal zone where they must face constant abiotic fluctuations, e.g. in temperature, irradiation, and salinity, in relation with the tidal cycle. In addition to these natural constraints, they must deal with pollutants, including heavy metals (HMs), resulting from human activities. These pollutants represent a major threat for marine ecosystems, impacting benthic flora and fauna assemblages [2-4]. Copper $(\mathrm{Cu})$ is a vital micronutrient, essential for all forms of life. It acts as cofactor for many enzymatic systems, and participates in crucial physiological processes including photosynthesis and respiration. However, excessive $\mathrm{Cu}$ concentrations are harmful for most living organisms. For this reason, free $\mathrm{Cu}$ is found only in traces in eukaryotic cells, where it is tightly controlled by a set of specific transporters and cytosolic chaperones that deliver it to their respective target proteins or organelles [5]. At high concentrations, both cupric and cuprous $\left(\mathrm{Cu}(\mathrm{II}) / \mathrm{Cu}(\mathrm{I}), \mathrm{E}^{0}=+0.15 \mathrm{~V}\right)$ ions can participate in redox reactions affecting organisms at the cellular level mainly by three well-established processes: (i) direct protein inactivation by undesired amino acid-metal interactions due to the affinity of $\mathrm{Cu}$ (II) for thiol-, imidazole-, and carboxyl- groups; (ii) in presence of superoxide or reducing agents $\mathrm{Cu}(\mathrm{II})$ can be reduced to $\mathrm{Cu}(\mathrm{I})$, which is capable of catalyzing the formation of hydroxyl radicals via the non-enzymatic Fenton's reaction [6]; (iii) displacement of essential cations from specific binding sites. These effects impact a wide range of cellular processes in photosynthetic organisms, interfering for instance with fatty acid and protein metabolism, or inhibiting respiration and nitrogen fixation processes [7]. Copper affects in particular photosystem electron transfer components, leading to the generation of reactive oxygen species (ROS) and peroxidation chain reactions involving membrane lipids $[8,9]$. For these reasons, this metal has been extensively utilized as antifouling agent to prevent the proliferation of algal flora on immersed surfaces.

Most organisms deploy an array of mechanisms to control cellular $\mathrm{Cu}$ levels, for detoxification, and to repair damaged cellular structures, which are triggered via the activation of signaling pathways. Signal transduction involves elements shared by plants and animals, but also molecules specific to each lineage [10]. Plants may trap free $\mathrm{Cu}$ by increasing levels of chelating agents such as chaperones, metallothioneins, phytochelatins, or organic acids [11]. This process is linked to an increase of transmembrane activity, in which $\mathrm{Cu} \mathrm{P}_{1 \mathrm{~B}}$-type ATPases and multidrug resistance $\mathrm{ABCC}$ transporters (formerly known as multidrug resistance-related proteins) may have key roles to sequester or exclude chelated forms of $\mathrm{Cu}$ or other toxic adducts $[12,13]$.

Knowledge of the molecular bases of $\mathrm{Cu}$ stress regulation in brown algae is still scarce and scattered. Previous studies in this domain have focused on a few specific physiological aspects such as photosynthesis [14,15], oxidative stress [16,17], or metal chelation $[18,19]$, and most constitute field studies of long-term adaptation to chronic $\mathrm{Cu}$ exposure. Recently, two publications have reported large-scale proteomic analyses to identify mechanisms underlying acclimation to high $\mathrm{Cu}$ levels [20,21]. These studies showed the increase of brown algal specific antioxidant mechanisms and changes in photosynthesisrelated proteins to cope with chronic $\mathrm{Cu}$ stress. However, there is still limited molecular data, especially at the transcriptomic level, on how brown algae sense short-term variations in metal content and induce the regulation of intracellular $\mathrm{Cu}$ concentrations through specific signaling processes. Previous work on the brown alga Laminaria digitata showed that short term exposure to $\mathrm{Cu}$ stress triggers the synthesis of 12-oxophytodienoic acid (12-OPDA) and prostaglandins, concomitantly with changes in expression of selected genes involved in stress response [22]. These results suggest that brown algae may synthesize plant-like octadecanoid, but also eicosanoid oxylipins, to induce stress-related detoxification responses.

So far, global molecular analyses of the brown algal stress response were hampered by the lack of genomic resources. The development of the biological model Ectocarpus siliculosus, including access to its genome sequence, represents a major breakthrough in algal research, and opens the gates to "omics"-based approaches [23,24]. Regarding $\mathrm{Cu}$-homeostasis, the annotation of the E. siliculosus genome allowed identifying several putative $\mathrm{Cu}-$ chaperones, $\mathrm{ABC}$ transporters, and $\mathrm{Cu}$-channels controlling cellular $\mathrm{Cu}$ traffic. Moreover, two recent reports by Dittami et al. [25,26] have established a starting point for the integrated analysis of transcript and metabolite profiling during the short-term response to saline and oxidative stress in E. siliculosus. They demonstrated the repression of primary metabolism and the activation of recycling of existing proteins through autophagy under the abiotic stress conditions tested.

In the present study, we employed large-scale transcriptome and metabolome analyses to gain insights into the short-term acclimation of E. siliculosus to $\mathrm{Cu}$ stress, and extended the analysis of gene expression data to results previously published for other abiotic stressors. The integration of these results highlighted the $\mathrm{Cu}$ induction of a large panel of signaling mechanisms likely to constitute the driving force behind the observed transcriptomic and metabolic shifts. In particular, 
oxylipin metabolism and several distinct genes coding for transcription-associated proteins were up-regulated. Moreover, transcriptomic meta-analysis of $\mathrm{Cu}$ and other abiotic stressors showed tight links between $\mathrm{Cu}$ and oxidative stress, and confirmed previous observations such as the repression of genes encoding enzymes involved in primary amino acid biosynthesis, balanced with the induction of autophagic processes. In addition, this analysis allowed the identification of $\mathrm{Cu}$ stress specific mechanisms such as the up-regulation of multidrug resistance $\mathrm{ABC}$ transporters, putative $\mathrm{Cu} \mathrm{P}_{1 \mathrm{~B}}$-type ATPases, and of a vanadium bromoperoxidase involved in halide metabolism.

\section{Results}

$\mathrm{Cu}$ stress treatments alter photosynthetic capabilities of E. siliculosus

To monitor the short-term acclimation to stress rather than cell death, the intensity of $\mathrm{Cu}$ stress had to be carefully selected. In previous chronic $\mathrm{Cu}$ stress experiments, we showed that $\mathrm{Cu}(\mathrm{II})$ at a concentration of $250 \mu \mathrm{g} \mathrm{L}^{-1}$ led to a drastic decrease of photosynthetic activity (Fv/Fm) after 1 to 6 days of treatment [21]. In this study, we aimed to monitor the acute $\mathrm{Cu}$ stress response of E. siliculosus. Therefore algae were incubated in presence of $\mathrm{Cu}$ (II) during $8 \mathrm{~h}$ at final concentrations of $250 \mu \mathrm{g} \mathrm{L} \mathrm{L}^{-1}$ and at $500 \mu \mathrm{g} \mathrm{L}{ }^{-1}$. These concentrations are comparable to those registered in $\mathrm{Cu}$ polluted marine sites where $E$. siliculosus has been observed [27,28], and correspond to an approximately 400-fold enrichment of the total dissolved $\mathrm{Cu}$ content in the natural seawater used to set-up the experiments. Changes in the photosynthetic yield were then followed on an hourly basis. Compared to the control treatment, algae incubated with $500 \mu \mathrm{g} \mathrm{L} \mathrm{L}^{-1}$ displayed significantly lower $\mathrm{Fv} / \mathrm{Fm}$ ratios after $6 \mathrm{~h}$ (U test, $\mathrm{p}<0.05$ ), while $250 \mu \mathrm{g} \mathrm{L}^{-1}$ induced a significant decrease ( $\mathrm{U}$ test, $\mathrm{p}<0.05$ ) only after $8 \mathrm{~h}$ of treatment (Figure 1 ). Taking these results into consideration, algae were sampled after $4 \mathrm{~h}$ and $8 \mathrm{~h}$ of incubation in medium with $250 \mu \mathrm{g} \mathrm{L}^{-1} \mathrm{Cu}(\mathrm{II})$ to monitor molecular changes occurring prior and during the observed reduction of photosynthetic activity.

\section{Meta-transcriptomic analysis highlights copper specific} genes, shared responses with oxidative stress treatments, and core abiotic stress genes

Copper stress treatment resulted in 909 significantly regulated contigs/singletons under $\mathrm{Cu}$ stress (regardless of time), 546 of which were up-regulated and 363 down-regulated compared to control conditions (twoway ANOVA, FDR of 5\%). None of the examined contigs/singletons showed a significant interaction between time and treatment, indicating little difference in the transcriptomic response to $4 \mathrm{~h}$ and $8 \mathrm{~h}$ of $\mathrm{Cu}$ treatment. Only $11 \%$ of the contigs/singletons induced in response to $\mathrm{Cu}$ stress were automatically classified by the GOLEM and KOBAS annotation tools (data not shown); therefore manual classification was done for genes presenting a fold-change ratio $>2$ compared to the control conditions. This dataset represents 560 genes (627 contigs/singletons), which were assigned to 13 categories (Figure 2, Additional file 1).

$\mathrm{Cu}$ stress transcriptomic data were further compared to previous results obtained with the same array and protocol for short-term $(6 \mathrm{~h})$ hyposaline $(56 \mathrm{mM} \mathrm{NaCl}$ final concentration), hypersaline $(1,470 \mathrm{mM} \mathrm{NaCl}$ final concentration) and oxidative ( $1 \mathrm{mM} \mathrm{H} \mathrm{H}_{2}$ final concentration) stress [25] [ArrayExpress:E-TABM-578]. To reduce the

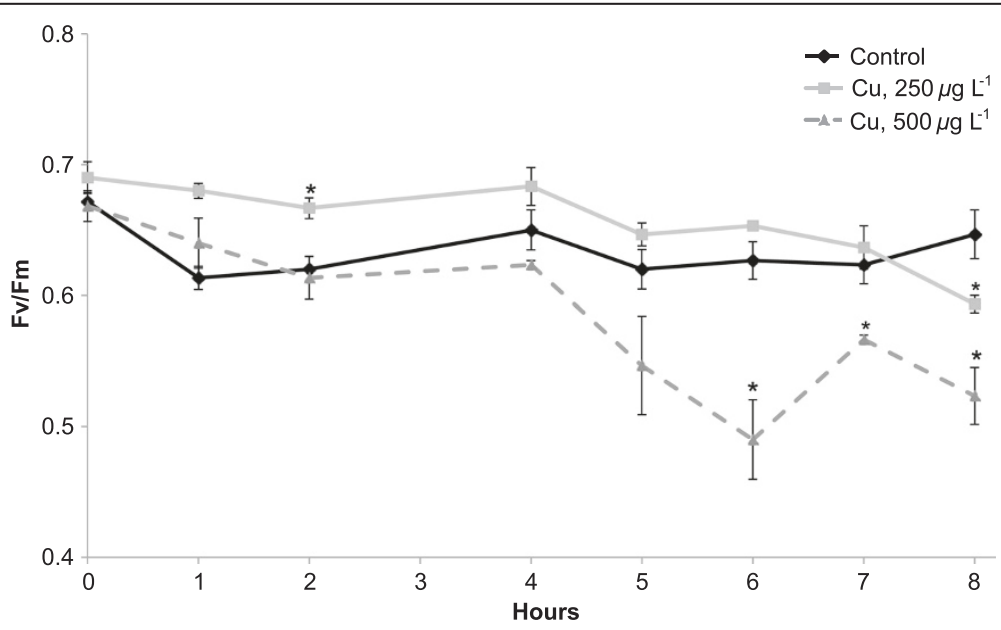

Figure 1 Physiological effects of acute copper (Cu) toxicity on E. siliculosus strain Ec32. Changes in the photosynthetic yield (Fv/Fm) were monitored during $8 \mathrm{~h}$ in absence of $\mathrm{Cu}$ (diamonds), and in presence of 250 (squares) and $500 \mu \mathrm{g} \mathrm{L}^{-1}$ (triangles) of $\mathrm{CuCl}_{2}$ (final concentration). Values represent means of three independent replicates and bars represent the standard error. Asterisks highlight significantly different values from the respective control condition ( $U$-test, $\mathrm{p}<0.05$ ). 


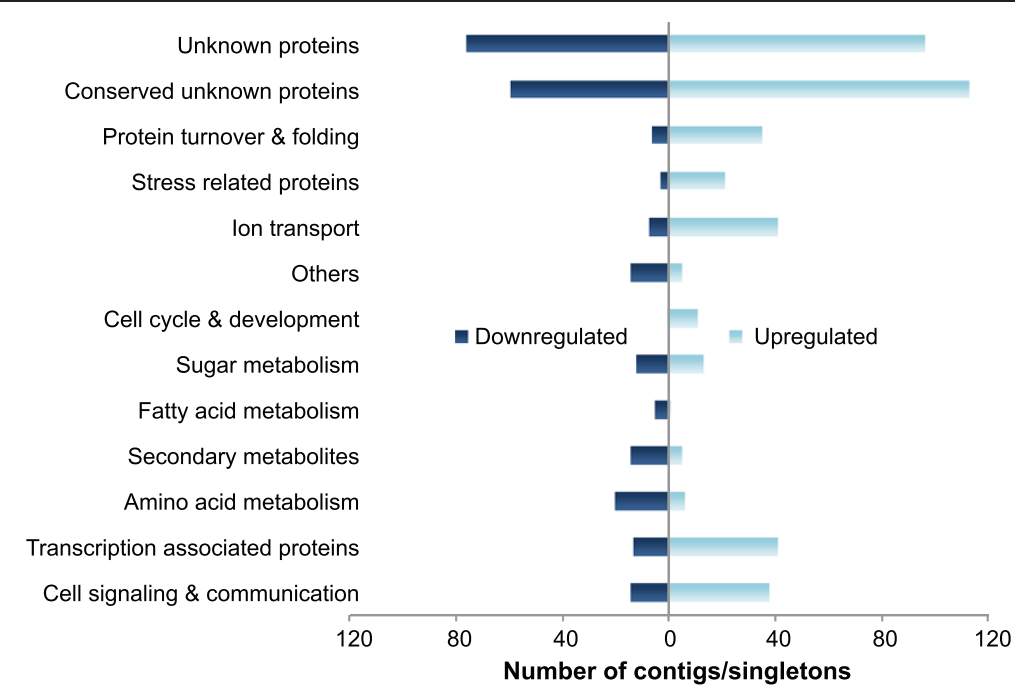

Figure 2 Functional distribution of contigs/singletons up-regulated and down-regulated in Cu-stressed E. siliculosus. Contigs/singletons were manually classified according to their annotation in the E. siliculosus genome database. The figure shows the number of significantly down- (left) and up-regulated (right) contig/singletons in each category (two-way ANOVA, FDR $<5 \%$ ).

number of false negatives no FDR correction was applied for this meta-analysis, and all transcripts previously found to be significantly regulated $(\mathrm{p}<0.05$, fold-change compared to control $>2$ ) after either $6 \mathrm{~h}[25]$ or 4 or $8 \mathrm{~h}$ (this study) were taken into account. Seventy-five contigs/ singletons were up-regulated in all considered stress conditions (Additional file 2A). Seventy-six percent of them (i.e. 57) code for proteins with unknown functions, and $48 \%$ (i.e. 36) are orphans (Additional file 3), that is as of March 2013, they had no match outside E. siliculosus in the NCBI nr database at an e-value cutoff of 1e-5. Regarding down-regulated transcripts, we identified 64 contigs/singletons (Additional file 2B) of which 55\% (i.e. 35) correspond to unknown proteins and 27\% (i.e. 17) are orphans.

Hierarchical clustering (Additional file 4) revealed that $\mathrm{H}_{2} \mathrm{O}_{2}$ stress samples formed a cluster with $\mathrm{Cu}$-stress samples, likely reflecting the fact that $\mathrm{Cu}$ (II) treatment unbalances the cellular redox state, leading to oxidative stress. Indeed, $42 \%$ of the contigs/singletons regulated (336 of the induced and 314 of the repressed) in response to copper stress were also regulated at least in response to $\mathrm{H}_{2} \mathrm{O}_{2}$ (Additional file 1). In the following sections, we focus on the manual analysis of selected gene families or functional categories of genes representing three profiles of expression: genes regulated by all available stressors, genes regulated at least by $\mathrm{Cu}$ and $\mathrm{H}_{2} \mathrm{O}_{2}$, and finally genes specifically regulated by copper stress. Lists of these genes as well as available annotations are provided in Additional file 3. Gene set enrichment analyses were performed for these three different groups of genes using Blast2GO, but did not yield any significantly overrepresented GO terms at an FDR $<5 \%$.

\section{Cell signaling and communication}

A phospholipase C (PLC) gene (comprising two genomic loci, Esi0000_0131 and Esi0000_0133) was up-regulated specifically under $\mathrm{Cu}$ stress. The locus Esi0085_0013, encoding a calcium-dependent phospholipid binding protein of the Copine family that is related to abiotic stress processes in land plants, was induced under both $\mathrm{Cu}$ and $\mathrm{H}_{2} \mathrm{O}_{2}$ stress. In addition, a gene encoding a $\mathrm{Ca}$ dependent protein kinase (Esi0073_0115) and a serine threonine kinase (Esi0038_0037) were up-regulated by both stressors. Conversely, a large set of genes involved in myo-inositol metabolism were down-regulated under these treatments. This was true for a cytidine diphosphate diacylglycerol (CDP-DAG) synthase (Esi0016_0173), a putative phosphatidylinositol-4-phosphate (PI4P) 5-kinase (Esi0030_ 0108), a myo-inositol-1-phosphate synthase (Esi0279_0022), a phosphatidylinositol transfer protein SEC14 (Esi0499_ 0013), and a putative inositol monophosphatase (Esi0133_ 0061).

In relation to downstream lipid metabolism and signaling cascades, a gene encoding a cytochrome P450 enzyme (Esi0060_0078) was among the most highly upregulated genes during copper treatment (41-fold after $4 \mathrm{~h}, 8$-fold after $8 \mathrm{~h}$ ) and also responded to oxidative stress (Additional file 3). The corresponding protein displays approximately $30 \%$ identity and $45 \%$ similarity with the cytochrome P450 domain of plant allene oxide synthases (AOSs) of the CYP74 family involved in the jasmonate biosynthetic pathway. A multiple alignment of this protein with members of the CYP74 family highlights the existence of several motifs common to AOSs, such as the IHCD motif and the conserved $F$ and $S$ catalytic amino acid residues (Additional file 5A). Finally, 
protein structure homology modelling using the Phyre2 software predicts high structural similarity between Esi0060_0078 and the AOS of Parthenium argentatum (Additional file 5, panel B; PDB: 3dan; 100\% confidence, 91\% coverage).

\section{Transcription factors (TFs)}

Among the 283 TFs in the E. siliculosus genome [29], our study identified 19 up-regulated and 6 downregulated genes (Table 1). Eight of these genes were specifically up-regulated by $\mathrm{Cu}$ stress, whereas seven others were co-induced by $\mathrm{Cu}$ and $\mathrm{H}_{2} \mathrm{O}_{2}$. Among them, two potential arsenite-inducible AN1-ZFPs, Esi0002_0015 (specifically up-regulated by $\mathrm{Cu}$ ), and Esi0348_0030 (induced by $\mathrm{Cu}, \mathrm{H}_{2} \mathrm{O}_{2}$ and hyposaline stress) were found. Interestingly, Esi0002_0015 was more similar to animal AN1-ZFPs, and Esi0348_0030 to plant-type stress associated proteins. Also in relation to stress TFs, the heat shock factor Esi0279_0021 was among the genes most strongly repressed in response to $\mathrm{Cu}$ stress, with a 26-fold change after $4 \mathrm{~h}$ of treatment (Table 1). Furthermore, two $\mathrm{Cu}$ specifically up-regulated genes, Esi0100_0085 and Esi0226_0031, contained the RWP-RK domain found in plant proteins involved in nitrogen-controlled development [30]. Finally, we recorded the transcriptional up-regulation of a gene coding for a protein containing a zinc finger

Table 1 Significantly (FDR < 0.05) Cu-regulated transcription factors (TFs) in E. siliculosus

\begin{tabular}{|c|c|c|c|c|c|c|c|}
\hline Gene ID & TF family & Domain 1 & Domain 2 & Annotation & Log2-ratio $4 \mathrm{~h}$ & Log2-ratio $8 \mathrm{~h}$ & Meta-analysis \\
\hline Esi0219_0040 & $\mathrm{bZIP}$ & bZIP_1 & bZIP_2 & Conserved unknown protein & 1.1 & 0.6 & Cu_Oxi_up \\
\hline Esi0051_0089 & $\mathrm{C} 2 \mathrm{H} 2$ & $\mathrm{zf}-\mathrm{C} 2 \mathrm{H} 2$ & - & Conserved unknown protein & 1.2 & 0.3 & Cu_up \\
\hline Esi0348_0030 & $\mathrm{C} 2 \mathrm{H} 2$ & zf-AN1 & zfAN1 & $\begin{array}{l}\text { Arsenite inducible RNA } \\
\text { associated protein } \\
\text { AIP-1-related SAP }\end{array}$ & 1.1 & 0.7 & Cu_Hypo_Oxi_up \\
\hline Esi0002_0015 & $\mathrm{C} 2 \mathrm{H} 2$ & zf-AN1 & - & $\begin{array}{l}\text { Arsenite inducible RNA } \\
\text { associated protein } \\
\text { AIP-1-related SAP }\end{array}$ & 1.8 & 1.8 & Cu_up \\
\hline Esi0513_0010 & $\mathrm{C} 2 \mathrm{H} 2$ & $\mathrm{zf}-\mathrm{C} 2 \mathrm{H} 2$ & - & $\begin{array}{l}\text { Similar to metal response } \\
\text { element-binding transcription } \\
\text { factor-1 MTF1 }\end{array}$ & 1.4 & 0.8 & Cu_Oxi_up \\
\hline Esi0301_0006 & $\mathrm{C} 2 \mathrm{H} 2$ & $\mathrm{R} 3 \mathrm{H}$ & - & Conserved unknown protein & 2.0 & 1.4 & Cu_Oxi_up \\
\hline Esi0040_0071 & $\mathrm{C} 2 \mathrm{H} 2$ & $\mathrm{C} 2 \mathrm{H} 2$ & - & Expressed unknown protein & 1.8 & 1.8 & Cu_Hyper_oxi_up \\
\hline Esi0071_0018 & $\mathrm{C} 2 \mathrm{H} 2$ & $\mathrm{C} 2 \mathrm{H} 2$ & PUB & $\begin{array}{l}\text { PUB domain, zinc finger protein } \\
\text { thioredoxin }\end{array}$ & 1.5 & 1.3 & Cu_Hypo_up \\
\hline Esi0100_0023 & $\mathrm{CCHC}$ & $\mathrm{CCHC}$ & - & Conserved unknown protein & 1.3 & -0.1 & Cu_Hypo_oxi_up \\
\hline Esi0151_0061 & $\mathrm{CCHC}$ & $\mathrm{CCHC}$ & - & Conserved unknown protein & 1.4 & 0.7 & Cu_Hypo_up \\
\hline Esi0118_0050 & $\mathrm{C} 3 \mathrm{H}$ & $\mathrm{zf}-\mathrm{CCCH}$ & - & Conserved unknown protein & 1.1 & 0.3 & Cu_up \\
\hline Esi0201_0038 & CCAAT_HAP3 & $N F-Y B$ & - & Conserved unknown protein & 1.8 & 1.4 & Cu_Hypo_up \\
\hline Esi0292_0018 & $\mathrm{FHA}$ & $\mathrm{FHA}$ & - & Nibrin & 1.3 & 0.6 & Cu_up \\
\hline Esi0041_0031 & GNAT & Acetyltransf_1 & - & Conserved unknown & 1.3 & 1.7 & Cu_up \\
\hline Esi0226_0031 & RWP-RK & RWP-RK & - & NIN-like transcription factor & 1.1 & 0.3 & Cu_up \\
\hline Esi0100_0085 & RWP-RK & RWP-RK & - & NIN-like transcription factor 4 & 1.4 & 0.5 & Cu_up \\
\hline Esi0004_0202 & SWI/SNF_SNF2 & Helicase_C & SNF2_N & DEAD-like helicase & 0.9 & 1.1 & Cu_up \\
\hline Esi0071_0075 & Zn_clus & Zn_clus & - & Conserved unknown & 3.1 & 1.6 & Cu_Oxi_up \\
\hline Esi0071_0081 & Zn_clus & Zn_clus & - & Conserved unknown & 1.4 & 0.4 & Cu_Oxi_up \\
\hline Esi0279_0021 & HSF & HSF & - & Heat Shock transcription factor & -4.7 & -2.0 & Cu_down \\
\hline Esi0149_0075 & $\mathrm{JmjC}$ & JmjC & - & $\begin{array}{l}\text { Transcription factor jumonji/ } \\
\text { aspartyl beta-hydroxylase }\end{array}$ & -1.3 & -0.9 & Cu_down \\
\hline Esi0290_0010 & mTERF & mTERF & - & Conserved unknown protein & -2.7 & -0.7 & Cu_Hypo_Oxi_down \\
\hline Esi0095_0057 & MYB-related & Myb & - & Conserved unknown protein & -2.4 & -1.3 & Cu_Hypo_Oxi_down \\
\hline Esi0013_0140 & RWP-RK & RWP-RK & - & NIN-like 6 & -2.6 & -1.6 & Cu_Hypo_Oxi_down \\
\hline Esi0356_0029 & AP2/EREBP & AP2 & - & $\begin{array}{l}\text { Pathogenesis-related } \\
\text { transcriptional factor and ERF }\end{array}$ & -1.9 & -1.1 & All_down \\
\hline
\end{tabular}

Log2-ratios represent the means of three biological replicates. In the column "Meta-analysis", Cu is for copper stress, Oxi for oxidative stress, Hyper for hypersaline stress, and Hypo for hyposaline stress condition. The direction of the changes under these different treatments is indicated by up and down for induction or repression, respectively. 
domain that was initially annotated as a metal responsive transcription factor (MTF)-1-like protein (Esi0513_0010) under both $\mathrm{Cu}$ and oxidative stress. However, although this protein showed some similarities to the DNA binding domain of metazoan MTF-1, no further homology to MTF-1 proteins was observed outside this domain, making it impossible to infer the function of Esi0513_0010 without further experimentation.

\section{Stress and detoxification mechanisms}

Many genes coding for proteins involved in general stress and detoxification mechanisms were regulated under both $\mathrm{Cu}$ and $\mathrm{H}_{2} \mathrm{O}_{2}$ stress. For instance, eight heat shock proteins (HSPs) of the 70, 40, and 20 classes were upregulated, possibly to facilitate the refolding of damaged proteins and to prevent protein aggregation (Additional file 3) under acute oxidative stress. The up-regulation of a DNA double-strand break repair rad50 ATPase (Esi0002_0198) was also observed. Finally, genes coding for proteins with important functions for antioxidant mechanisms were also induced by $\mathrm{Cu}$ and $\mathrm{H}_{2} \mathrm{O}_{2}$, including a glutathione reductase (Esi0019_0176), two glutathione-S-transferases (Esi0648_0004 and Esi0191_ 0054), and one thioredoxin (Esi0030_0031).

Besides the overlapping responses to $\mathrm{H}_{2} \mathrm{O}_{2}$ and $\mathrm{Cu}$ treatments, several genes regulated exclusively by $\mathrm{Cu}$ stress were identified, including two chloroplastic irondependant superoxide dismutases (Fe-SODs; Esi0219_002 and Esi0201_0013) and a vanadium dependent bromoperoxidase (vBPO; Esi0009_0080) which is a ROS detoxifying enzyme specific of brown algae (Additional file 3). Furthermore, a glutathione-S-transferase (Esi0002_0065), and two glutaredoxins, Esi0050_0061 (a glutaredoxin/malate transporter fusion protein) and Esi0036_0002, were also specifically up-regulated by $\mathrm{Cu}$. These latter enzymes are likely involved in HM-detoxification functions such as reduction of $\mathrm{Cu}$-glutathione adducts and export of $\mathrm{Cu}$-organic acid adducts. Several additional stress-related transport systems were specifically up-regulated by $\mathrm{Cu}$ stress. Among them were a multidrug and toxic compound extrusion protein (MATE; Esi0017_0140) and a putative heavy metal $\mathrm{P}_{1 \mathrm{~B}}$-type ATPase (HMA; Esi0023_0054) (Additional file 3). This protein contains a conserved HMA motif in the N-terminal cytoplasmic region, a central E1-E2 ATPase domain, and a haloacid dehalogenase domain in the C-terminal region (Additional file 6); PSI-BLAST shows $41 \%$ of identity between the E. siliculosus protein and the $A$. thaliana $\mathrm{Cu}^{+}$exporting $\mathrm{P}_{1 \mathrm{~B}}$ type ATPase HMA5 (AT1G63440).

We also observed $\mathrm{Cu}$ specific up-regulation of five of the 69 putative E. siliculosus ABC transporter proteins (ABCTs) (Additional file 3). Phylogenetic analysis, together with reference sequences from the human [31] and A. thaliana [32] superfamily of ABCTs, led to the classification of these five E. siliculosus proteins into four ABCT subfamilies (Figure 3). Of particular interest are Esi0109_0024 and Esi077_0044, which fall into the stress-detoxification ABC-B (MDR/TAP) and ABC-C (CFTR/MRP) subfamilies, respectively. In addition, Esi0359_ 0018 and Esi0154_0007 clustered with plant and human ABC-A transporters.

\section{Primary metabolism and protein turnover}

As illustrated by our PAM measurements, one basic process altered by copper stress was photosynthesis, which is directly linked to the generation of ROS when intracellular copper concentrations are not properly regulated. In our study, two genes coding for stress-related chlorophyll binding proteins (CBPs) of the LI818 family, Esi0002_0349 and Esi0085_0016, appeared up-regulated specifically by $\mathrm{Cu}$ stress, and a third, Esi0085_0049, was up-regulated under copper, oxidative, and hyposaline stress. A fourth Cu-induced CBP, Esi0458_0016, belonged to the LHCF clade [33]. We also observed a trend for down-regulation, at least under $\mathrm{Cu}$ stress, of a number of genes related to the xanthophyll cycle such as putative violaxanthin de-epoxidases, as well as a putative zeaxanthin epoxidase (Additional file 1). Regarding chlorophyll biosynthesis, $\mathrm{Cu}$ and $\mathrm{H}_{2} \mathrm{O}_{2}$ repressed genes encoding an $\mathrm{Mg}$ chelatase, a chlorophyll synthase, and a protoporphyrinogen oxidase. Although these changes did not pass our rather strict FDR correction, they were significant when analysed individually (Additional file 3).

Twenty of the genes repressed by $\mathrm{Cu}$ stress were associated to nitrogen assimilation and primary amino acid synthesis (Figure 4). Several of them were also downregulated under $\mathrm{H}_{2} \mathrm{O}_{2}$ stress, such as one nitrite reductase (NAD(P)H and ferredoxin; Esi0249_0028), one glutamate synthase (Esi0029_0131), one glutamate dehydrogenase 1 (Esi0028_0164), and three putative $\mathrm{NH}_{4}{ }^{+}$and $\mathrm{NO}_{3}{ }^{-}$transporters (Esi0526_0006, Esi0278_0026, and Esi0278_0032) (Additional file 3). These observations suggest the repression of the GS/GOGAT pathway under oxidative stress conditions. In addition, an agmatinase (Esi0039_0062), and a spermine synthase (Esi0000_0445) were specifically down-regulated by $\mathrm{Cu}$, indicating the repression of the arginine/ornithine-derived polyamine pathway. Three other genes, coding for proteins involved in nitrate, ammonium, urea and amino acid transport (Esi0278_0026, Esi0526_0006, and Esi0104_0047), were down-regulated in all stress conditions included in our meta-analysis.

In contrast to the transcriptomic repression of nitrogen assimilation, 35 contigs/singletons related to protein turnover processes (Figure 2) were induced in response to copper stress. Among them, 12 genes correspond to the ubiquitin system, and all of them except one encoding an ubiquitin related protein Esi0009_0093 were induced in response to several stressors (Additional file 3). 


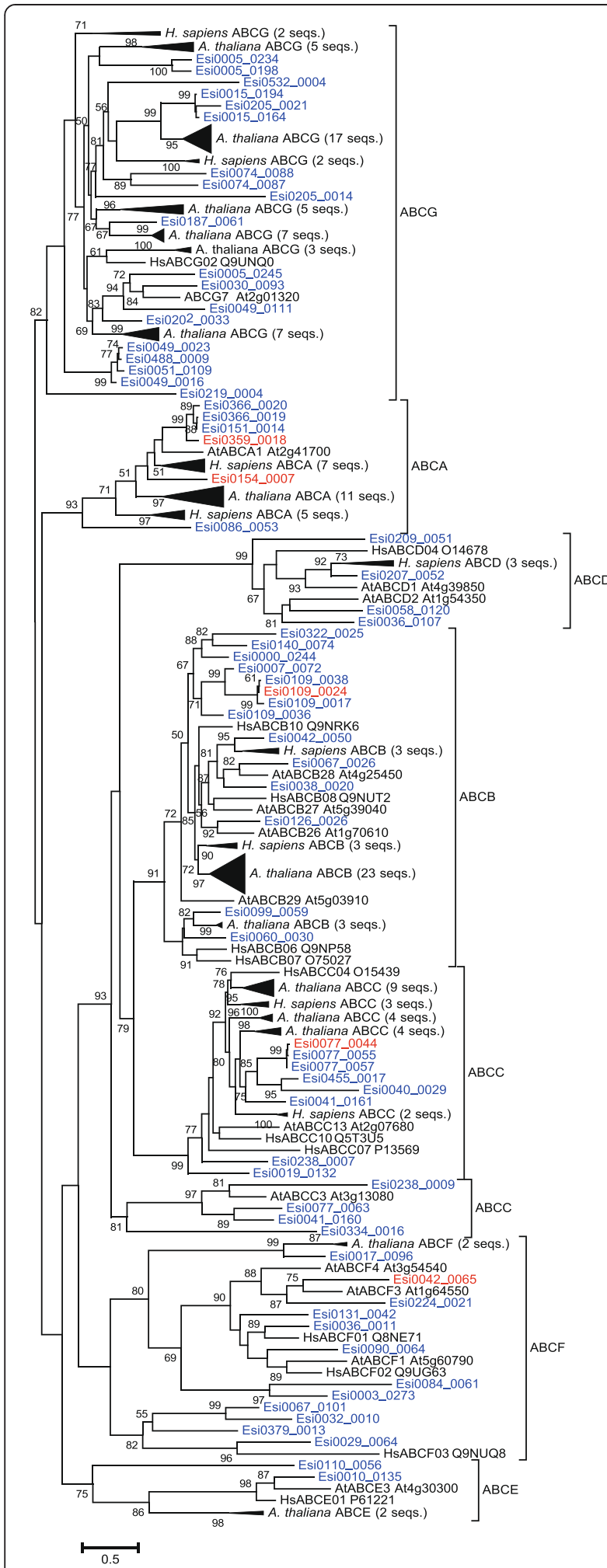

Figure 3 Phylogenetic tree of human, $A$. thaliana, and E. siliculosus (red and blue) $A B C$ transporters. E. siliculosus genes induced specifically by Cu stress are marked in red. Confidence values are the results of an approximate likelihood ratio test; only confidence values $\geq 50$ are shown.
Eight genes corresponded to proteasome-related proteins, suggesting the induction of stress-related autophagy mechanisms. Four of these genes were induced specifically in response to copper. Furthermore, we detected the upregulation of six RING type domain proteins that might correspond to E3-ligases (Additional file 1).

Parallel to changes in $\mathrm{N}$ metabolism, we observed down-regulation of genes involved in fatty acid synthesis and degradation. Moreover, twenty-one genes related to sugar metabolism were significantly regulated in response to $\mathrm{Cu}$ treatments (FDR < 5\%; Additional file 1). Most of them correspond to proteins involved in central carbon metabolism and storage, sugar transport, and structural modifications of cell wall polysaccharides, and were also regulated in response to other stressors (Additional file 3). Regarding sugar metabolism, it is interesting to note the presence of genes involved in mannitol and trehalose synthesis, both repressed in presence of $\mathrm{Cu}$ (Additional file 1). With respect to cell wall structure modifications, we noted that $\mathrm{Cu}$ and $\mathrm{H}_{2} \mathrm{O}_{2}$ treatments induced the upregulation of two genes encoding the alginate modifying enzymes mannuronan-C5-epimerases MEP6 and MEP7 (Additional file 3). A number of loci corresponding to other polysaccharide modifying enzymes were also induced in presence of copper, mainly after $4 \mathrm{~h}$ of treatment, such as several loci encoding glycoside hydrolases (GHs) and glycoside transferases (GTs) (Additional file 3). However, none of these $\mathrm{Cu}$-regulated GTs or GHs was induced in presence of $\mathrm{H}_{2} \mathrm{O}_{2}$.

\section{Cu-induced changes at the transcriptome level modulate metabolite composition}

To relate the transcriptional reprogramming induced by copper stress in E. siliculosus with changes in the metabolome, metabolite profiling was carried out for algal samples harvested after $4 \mathrm{~h}$ and $8 \mathrm{~h}$ of treatments. UPLC-MS experiments in positive ion mode for $\mathrm{Cu}$-stressed algae provided 392 monoisotopic peaks. Partial least squares discriminant analysis (Additional file 7) and hierarchical clustering (Additional file 8) of these compounds indicated a clear distinction between $\mathrm{Cu}$ stress and control samples, but the different treatment times could not be separated. Two major groups of metabolites emerged from this analysis, corresponding to compounds that either accumulate or decline in response to $\mathrm{Cu}$ stress. Within each of these groups two smaller clusters, with either a strong or a weak response to stress, were visible. The combination of UPLC-MS and GC-MS analysis allowed us to identify 47 compounds corresponding to fatty acids, oxylipins, and amino acids (Figure 5).

\section{Changes in amino acid contents}

In agreement with our results obtained for the global metabolite profiles, PLS-DA of samples according to 
their amino acid profile allowed to discriminate between control and stress conditions (Additional file 9, panel A), as well as between durations of treatments. The primary amino acids in E. siliculosus, alanine and glutamate [34] showed no significant variations in response to stress $(p>0.05$; Figure 5). In contrast, contents of aromatic (phenylalanine and tyrosine) and branched chain amino acids (valine, leucine, and isoleucine) increased at least 2 fold after $4 \mathrm{~h}$ and $8 \mathrm{~h}$ of $\mathrm{Cu}$ treatment (two-way ANOVA, $\mathrm{p}<0.05$ ), likely as a result of increased protein catabolism.

Variations in free fatty acid contents and oxylipin synthesis $\mathrm{Cu}$ stress induced a significant increase in the levels of free fatty acids (FFAs), especially after $8 \mathrm{~h}$ of treatment (two-way ANOVA $\mathrm{p}<0.05$ ) (Figure 5). In accordance with this analysis, the PLS co-projection of FFA variations discriminated treatments (control - stress) and exposure time (4-8 h) (Additional file 9, panel B).

Regarding FFAs, $\mathrm{Cu}$ treatment induced a 3-fold increase of linolenic acid (C18:3), arachidonic acid (C20:4), and eicosapentaenoic acid (C20:5) (two-way ANOVA, p < 0.05; Figure 5). This increase was correlated with the occurrence of octadecanoid and eicosanoid oxygenated derivatives but only after $8 \mathrm{~h}$ of stress and in three of the four biological replicates analyzed. Currently, we do not have any explanation why these observations did not hold true for the fourth biological replicate, which much resembled the other replicates of the same condition with respect to all other examined metabolites as well as gene expression profiles. In the three replicates mentioned above, 13hydroxy-9Z,11E-octadecadienoic acid (13-HODE) and 13S-hydroxy-9Z,11E,15Z-octadecatrienoic acid (13-HOTrE) contents increased under the $8 \mathrm{~h}$ stress treatment, with 16- and 3-fold changes respectively, suggesting the occurrence of a 13-lipoxygenase activity (Figure 5). Within the same context, the content of 12-oxophytodienoic acid (12-oxo-PDA) increased 3-fold after $8 \mathrm{~h}$ of $\mathrm{Cu}$ treatment and the non-enzymatic accumulation of cyclic $\mathrm{C} 18$ phytoprostanes $A_{1}$ was triggered, supporting the occurrence of ROS-mediated lipid peroxidation processes. Finally, $\mathrm{Cu}$ stress induced the accumulation of $\mathrm{C} 20: 4$ derivatives such as oxo-6E,8Z,11Z,14Z-eicosatetraenoic acid (oxo-ETE; 8fold change after $8 \mathrm{~h}$ of treatment), together with the cyclopentenones prostaglandin A2 and J2 (Figure 6).

Finally, it is worth mentioning that among the 392 monoisotopic peaks from ions detected through UPLCMS analysis, many unknown metabolites were regulated by exposure to $\mathrm{Cu}$ (Additional file 8 ). The analysis of these compounds was beyond the scope of this report, but their identity and function will be the subject of future studies.

\section{Discussion}

Copper is extremely toxic at high concentrations, and induces oxidative stress by altering electron transfer reactions such as photosynthesis and respiration. In our study, we observed a range of different acclimation processes on the molecular level (transcriptomic and metabolite profiling) before the alga exhibited a decrease in photosynthetic yield. Such a decrease in photosynthetic yield results in the alteration of several physiological processes in E. siliculosus, such as the formation of heavy metal-substituted chlorophylls [14], reduced carbon fixation and depletion of reducing equivalents. Effectively, since nitrate reduction directly relies on $\mathrm{NADH}$ and 

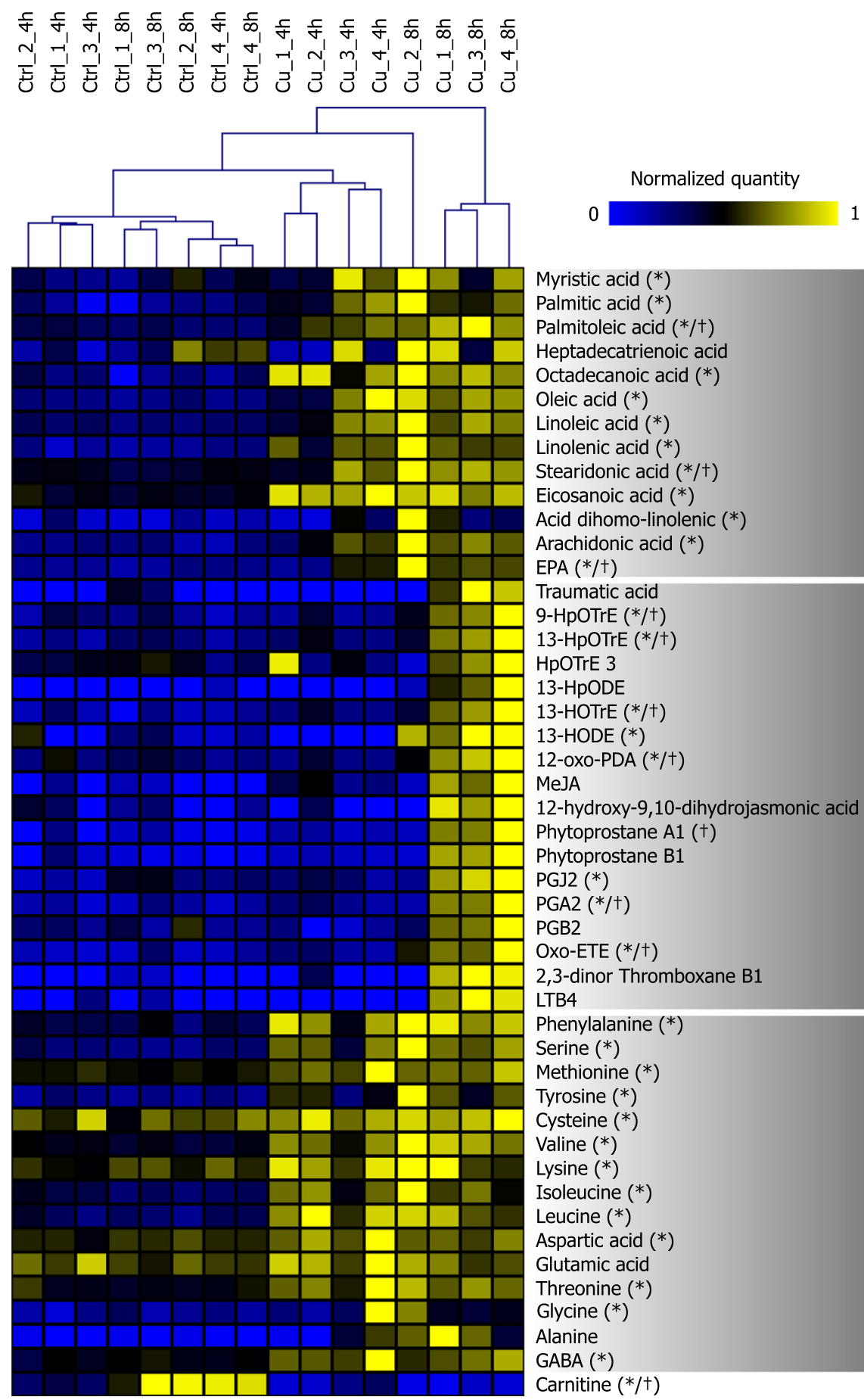

Myristic acid $(*)$

Palmitic acid $(*)$

Palmitoleic acid $(* / \dagger)$

Heptadecatrienoic acid

Octadecanoic acid $(*)$

Oleic acid $(*)$

Linoleic acid $(*)$

Linolenic acid $(*)$

Stearidonic acid $(* /+)$

Eicosanoic acid $(*)$

Acid dihomo-linolenic $(*)$

Arachidonic acid $(*)$

EPA $(* / t)$

Traumatic acid

9-HpOTrE $(* / \dagger)$

13-HpOTrE $(* / t)$

HpOTrE 3

13-HpODE

13-HOTrE $(* / \dagger)$

13-HODE $(*)$

12-oxo-PDA $(* / \dagger)$

MeJA

12-hydroxy-9,10-dihydrojasmonic acid

Phytoprostane A1 $\left({ }^{\dagger}\right)$

Phytoprostane B1

PGJ2 (*)

PGA2 $(* /+)$

PGB2

Oxo-ETE $(* / \dagger)$

2,3-dinor Thromboxane B1

LTB4

Phenylalanine $\left(^{*}\right)$

Serine $(*)$

Methionine $(*)$

Tyrosine $(*)$

Cysteine $(*)$

Valine $(*)$

Lysine $(*)$

Isoleucine $(*)$

Leucine $(*)$

Aspartic acid $(*)$

Glutamic acid

Threonine $(*)$

Glycine $\left(^{*}\right)$

Alanine

GABA $(*)$

Carnitine $(* / \dagger)$

Figure 5 Heat map of compounds identified by UPLC-MS and GC-MS in copper stress and control conditions. Samples were arranged according to a hierarchical clustering analysis (Euclidean distance), and the 47 compounds identified were grouped manually. Concentrations of each metabolite were normalized to a maximum of 1 (see Methods section). "**" and " $\dagger$ " indicate significant results (FDR $<5 \%$ ) in the two-way ANOVA for stress and the interaction term "stress* time", respectively. 9-HpOTrE, 9-hydroperoxy-10,12,15-octadecatrienoic acid; 13-HpOTrE, 13S-hydroperoxy-9Z,11E,15Z-octadecatrienoic acid; HpOTrE 3; oxylipin with the same m/z and raw formula as 11- or 15- hydroperoxy-9Z,11E,15Zoctadecatrienoic acid; 13-HpODE, 13-hydroperoxy-9Z,11E-octadecadienoic acid; 13-HOTrE, 13S-hydroxy-9Z,11E,15Z-octadecatrienoic acid; 13-HODE, 13-hydroxy-9Z,11E-octadecadienoic acid; 12-oxo-PDA, 12-oxophytodienoic acid; MeJA, methyl-jasmonate; PGJ2, prostaglandin J2; PGA2, prostaglandin A2, PGB2, prostaglandin B2; OXo-ETE, oxo-6E,8Z,11Z,14Z-eicosatetraenoic acid; LTB4, leukotriene B4; GABA, $\gamma$-aminobutyric acid. 


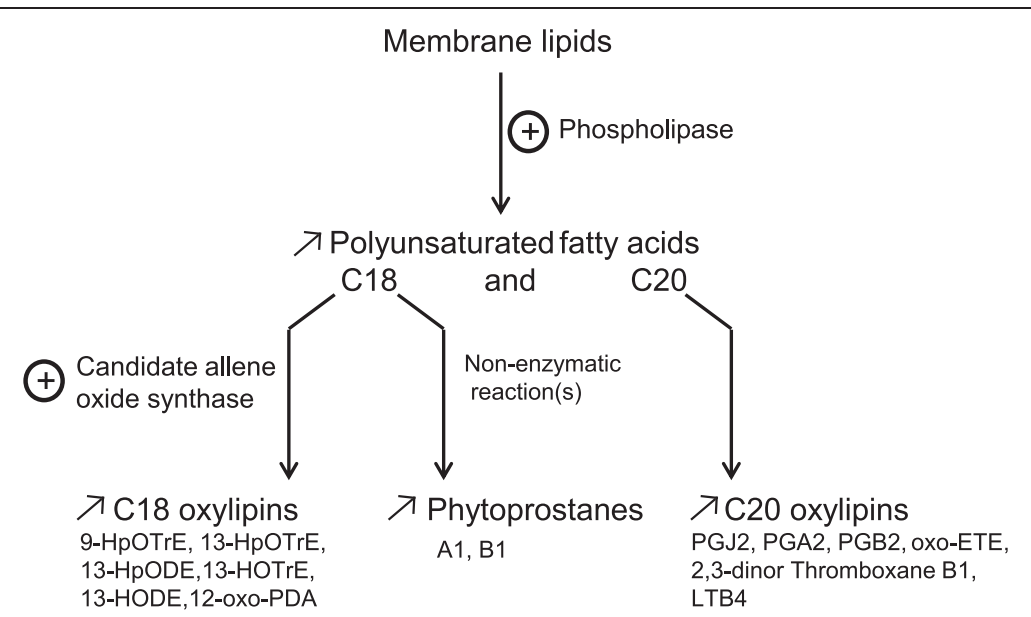

Figure 6 Changes in contents of free polyunsaturated fatty acids and oxylipins under copper stress. 9-HpOTrE, 9-hydroperoxy-10,12,15octadecatrienoic acid; 13-HpOTrE, 13S-hydroperoxy-9Z,11E,15Z-octadecatrienoic acid; 13-HpODE, 13-hydroperoxy-9Z,11E-octadecadienoic acid; 13-HOTrE, 13S-hydroxy-9Z,1 1E,15Z-octadecatrienoic acid; 13-HODE, 13-hydroxy-9Z,11E-octadecadienoic acid; 12-oxo-PDA, 12-oxophytodienoic acid; PGJ2, prostaglandin J2; PGA2, prostaglandin A2; PGB2, prostaglandin B2; Oxo-ETE, oxo-6E,8Z,11Z,1 14Z-eicosatetraenoic acid; LTB4, leukotriene B4.

$\mathrm{FADH}_{2}$ produced by photosynthesis [35], any condition altering photosynthesis (e.g. abiotic stress) may directly affect the regulation of $\mathrm{N}$ assimilation and the associated primary amino acid metabolism [36] or vice versa. We observed that $\mathrm{Cu}$-stressed E. siliculosus downregulated genes coding for enzymes related to $\mathrm{N}$ assimilation. This down-regulation was not related to a decrease of the pool of free primary amino acids. Moreover, an increase in the content of aromatic amino acids was recorded together with an induction of genes encoding proteins involved in the autophagy process, in particular those related to ubiquitination such as putative E3 ubiquitin ligases, and proteins involved in the proteasome complexes. These observations are similar to previous results published in E. siliculosus on response to other stress conditions [25], and suggest that alteration of $\mathrm{N}$ assimilation and carbon fixation is compensated by degradation of damaged proteins and recycling of amino acids. Similar processes have been identified in land plants during stress response or in diatoms under nitrogen starvation $[37,38]$. Concomitantly to the down-regulation of genes involved in $\mathrm{N}$ assimilation under copper stress, we observed an increase of free fatty acids. Similar links between amino- and fatty acid metabolism have previously been observed in other algae, such as Chlamydomonas reinhardtii [39]. Altogether, these data suggest that a substantial part of the response of E. siliculosus to short term copper stress consists in balancing primary metabolic processes. Although we can currently only speculate about the exact physiological benefits of each of the observed adjustments, two important functions may be (1) the compensation for stress-induced changes in photosynthesis and (2) the reduction of the energetic budget for nitrogen assimilation. These changes in primary metabolic processes are undoubtedly tightly tied to the specific stress responses and signaling mechanisms discussed below.

Much of the shared $\mathrm{Cu}$ and $\mathrm{H}_{2} \mathrm{O}_{2}$ response consisted in genes related to signal transduction and ROS scavenging. This result points out that the $\mathrm{Cu}$-induced ROS formation activates a large set of stress acclimation mechanisms. Apart from the overlapping response, several genes were regulated exclusively under $\mathrm{Cu}$ stress, suggesting that this heavy metal may induce the production of ROSs different from those produced under $\mathrm{H}_{2} \mathrm{O}_{2}$ stress, such as $\mathrm{O}_{2}{ }^{-}$or ${ }^{*} \mathrm{HO}$. In relation to signal transduction, we detected down-regulation of several E. siliculosus genes encoding enzymes involved in myo-inositol (MI) metabolism, a conserved process in plants and metazoans [10,40]. Recent studies in Arabidopsis have demonstrated the importance of MI in oxidative and phytohormone-related stress responses. Using catalasedeficient $A$. thaliana mutant plants, Chaouch and Noctor [41] observed that MI abolished salicylic acid-dependent cell death and pathogen defense responses triggered by peroxisomal $\mathrm{H}_{2} \mathrm{O}_{2}$. As mentioned by Meng et al. [42] and Donahue et al. [43], a connection has been previously observed between MI synthesis and cell death by studying L-myo-inositol 1-phosphate synthase mutants. While our data indicates that a similar link between oxidative stress and the MI pathway may exist in E. siliculosus, it remains to be assessed whether the underlying functions or regulatory mechanisms are the same as those found in A. thaliana. Besides the direct signaling functions of MI, multi-phosphorylated forms of inositol such as $\mathrm{IP}_{5}$ or $\mathrm{IP}_{6}$ are key cofactors of the plant auxin $\left(\mathrm{SCF}^{\mathrm{TIR} 1}\right)$ and jasmonate $\left(\mathrm{SCF}^{\mathrm{COI} 1}\right)$ ubiquitin ligase receptor complexes, therefore playing fundamental roles 
in phytohormone perception [44]. Methyl-jasmonate (MeJA) was detected in our experiments, but its contents did not change significantly $(p>0.05)$ under the tested conditions. Previous studies have shown that exogenous treatments with MeJA activate defensive mechanisms in several brown algae [45-47]. The synthetic pathway of MeJA has not yet been functionally characterized in brown algae and, moreover, the E. siliculosus genome contains neither homologs of land plant JA receptors nor components of the core transcriptional regulatory complex such as MYCs, JAZs, NINJA and COI1 [24,48]. This suggests that this molecule may not exert the same functions in brown algae as in land plants or that this compound has evolved to serve similar functions but using different regulatory systems. However, $8 \mathrm{~h}$ of $\mathrm{Cu}$ stress triggered the accumulation of $\mathrm{C} 18$ plant-like cyclic oxylipins such as 12-OPDA, $\mathrm{PPA}_{1}$ and $\mathrm{PPA}_{2}$, together with C20:4 cyclic prostaglandins such as $\mathrm{PGA}_{2}$ and $\mathrm{PGJ}_{2}$ in E. siliculosus, and this is in agreement with previous observations made in the kelp L. digitata [22]. In other organisms these compounds are derived from enzymatic (PGA2, PGJ2, and 12-OPDA) or non-enzymatic (PPA1) processes. All of these fatty acids derivatives contain $\alpha, \beta-$ unsaturated carbonyl groups and belong to the group of reactive electrophilic species [49]. In land plants, previous studies have demonstrated that 12-OPDA and phytoprostanes play important roles in environmental stress and pathogenesis, acting independently of MeJA, by activating general detoxification and stress responses including HSPs and $A B C$ transporters [50,51]. In this sense, one of the most highly up-regulated genes under copper treatment featuring some sequence similarity with members of the cytochrome P450 CYP74 family is an interesting candidate for AOS activity in E. siliculosus, but further experiments will be required to determine the function of this protein with certainty. In our study, we also observed changes in the expression of genes similar to those regulated by RES in land plants. It is therefore reasonable to speculate about (partially) conserved physiological roles of these oxylipins in E. siliculosus. Detailed transcriptomic experiments using each of these compounds as elicitor must be carried out to test these hypotheses. However, the increase of octadecanoid and eicosanoid oxygenated fatty acid derivatives suggest that brown algae may use plant-like octadecanoid signals and animal-like eicosanoid oxylipins, which are absent in vascular plants, to regulate protective mechanisms or stress responses.

Metal transport is a key process in the interaction of algae with their environments [52], and $\mathrm{Cu}$ treatment induced several potential membrane transport mechanisms in E. siliculosus. Of special interest was the upregulation of a putative ortholog of $A$. thaliana $\mathrm{Cu}^{2+}$ $\mathrm{P}_{1 \mathrm{~B}}$-type ATPases. Such proteins play an important role in $\mathrm{Cu}$ compartmentalization and excretion in plant roots, and corresponding mutants in $A$. thaliana are $\mathrm{Cu}$ hypersensitive [12]. In the same vein, five $A B C$ transporters were up-regulated in response to $\mathrm{Cu}$ stress, two of which belong to the $B$ and $C$ sub-families known to participate in the transport of xenobiotics, and of glutathione or phytochelatin conjugates in land plants and animals [31,32]. Additionally, members of the sub-family $\mathrm{C}$, such as the human MRP1, have been shown to act as transporter of eicosanoids such as leukotrienes [31], suggesting a possible link between the concomitant induction of an MRP homolog in E. siliculosus and of C20 oxylipin production in our study. Furthermore, several putative transporters of the sub-family A are regulated under $\mathrm{Cu}$ stress in E. siliculosus and might be involved in lipid trafficking processes in regard to the function of these proteins in land plants and mammals [53,54]. Detoxification transporters of the MATE family and GRX/ malate fusion proteins also seem to play a role in $\mathrm{Cu}$ detoxification in E. siliculosus. In rice, MATEs are involved in aluminium $(\mathrm{Al})$ resistance by secreting $\mathrm{Al}$ citrate conjugates [55]. Assuming similar functions in E. siliculosus, our observation would suggest that the up-regulation of genes encoding these transporters is related to the secretion of $\mathrm{Cu}$-conjugates, and thus that some processes involved in $\mathrm{Cu}$ detoxification are conserved across very distant lineages. In contrast, among the mechanisms that seem to be specific to brown algae, one is based on halide metabolism. The E. siliculosus genome contains only one gene coding for a putative vBPO, and this gene was up-regulated under $\mathrm{Cu}$ stress. The accumulation of this vBPO protein and an increase in the corresponding enzyme activity in both a coppertolerant and a copper-sensitive strain of E. siliculosus (i.e. the strain used in this study) in response to chronic $\mathrm{Cu}$ stress conditions have previously been reported [21], supporting the potential role of this enzyme in specific brown algal ROS detoxification processes.

\section{Conclusions}

This study provides an overview of copper stress acclimation in E. siliculosus, and highlights a number of processes that seem to be conserved with metazoans or land plants. Of interest for future brown algal research is the potential cross-talk between ROS, MI, and oxylipin signaling. Considering that two thirds of the regulated genes identified through this work encode proteins of unknown function, many additional components of the stress response remain to be discovered. The number of available medium to high throughput datasets related to stress response in brown algae is still limited [56], and the analysis of such results paves the way to decipher some of the molecular mechanisms leading to acclimation of these organisms to their frequently changing environment. They will be complemented by follow-up 
studies benefiting from the development of new techniques and protocols for brown algae, such as reverse genetics (transformation, RNAi, and tilling) or the assessment of nucleic acid-protein and protein-protein interactions.

\section{Methods}

Cultivation of plant material and experimental set-up

E. siliculosus (Ectocarpales, Phaeophyceae) unialgal strain 32 (CCAP accession 1310/4) was cultivated in Provasolienriched natural seawater at $14^{\circ} \mathrm{C}$ using a $14 / 10 \mathrm{~h}$ photoperiod and a photosynthetically active radiation (PAR) intensity of $40 \mu \mathrm{mol} \mathrm{m} \mathrm{m}^{-2} \mathrm{~s}^{-1}$ provided by Philips daylight fluorescent tubes, in $10 \mathrm{~L}$ Nalgene flasks under constant aeration. Experiments were carried out with $0.45 \mu \mathrm{m}$ filtered natural seawater (FSW) that was collected offshore at Roscoff $\left(+48^{\circ} 46^{\prime} 40,-3^{\circ} 56^{\prime} 15\right)$, a site with no direct chemical influence from the shore and presenting dissolved copper concentrations ranging from 5 to $10 \mathrm{nM}$ (Riso et al. personal communication). FSW was then treated to avoid potentially chelating organic matter by adding $0.2 \mathrm{~g} \mathrm{~L}^{-1}$ activated charcoal (Merck, Germany) overnight. Treated water was filtered at $0.45 \mu \mathrm{m}$ to remove charcoal. Copper stress was triggered by transferring the algae to fresh seawater free of organic matter and enriched with $\mathrm{Cu}$ (II) as $\mathrm{CuCl}_{2}$ (Merck, Germany) at nominal final concentrations of 250 or $500 \mu \mathrm{g} \mathrm{L}^{-1}$ (i.e. $1.8 \mu \mathrm{M}$ and $3.7 \mu \mathrm{M}$ ), in $1 \mathrm{~L}$ glass flasks washed overnight with $1 \% \mathrm{HCl}$ to limit $\mathrm{Cu}$ adsorption. Neither nutrients, nor EDTA, were added during the experiments. After 4 and $8 \mathrm{~h}$, replicate cultures were harvested by gentle filtration, algal material was briefly dried using a paper towel, and immediately frozen in liquid nitrogen. For metabolomic profiling, four replicate cultures $\left(250 \mu \mathrm{g} \mathrm{L}^{-1}\right.$ of $\mathrm{CuCl}_{2}$, as well as corresponding controls) were harvested at each time point. Transcriptomic profiling was carried out in triplicate.

\section{Measurement of PSII maximum quantum yield}

To monitor the stress intensity caused by $\mathrm{Cu}$ treatments in algal tissues, maximum quantum yield of PSII (dark adapted) was measured in one-hour intervals as $F_{v} / F_{m}$ using a Walz Phyto-PAM (Waltz, Germany) as previously described [21]. Since photosynthesis is stress-sensitive, the quantum yield decreased under sub-optimal (stressful) conditions. Statistically significant differences in Fv/Fm values between treatments were determined by a $\mathrm{z}$ adjusted Mann-Whitney U test performed using Statistica 5.1 (Statsoft, USA; $\mathrm{p}<0.05$ ).

\section{Double strand cDNA sample preparation and microarray hybridization}

RNA was extracted from approximately $100 \mathrm{mg}$ (wet weight) of tissue following Apt et al. [57] with modifications as described by Le Bail et al. [58], using a CTAB-based extraction buffer and subsequent phenol-chloroform purification, LiCl-precipitation, and DNAse (Turbo DNAse, Ambion, Austin, USA) steps. RNA quality and quantity was then verified on a $1 \%$ agarose gel stained with ethidium bromide and a NanoDrop ND-1000 spectrophotometer, respectively. Double strand cDNA synthesis and amplification were carried out with the SMART cDNA synthesis kit (Clontech, Mountain View, USA) and the M-MuLV reverse transcriptase (Finnzymes, Espoo, Finland) starting from $100 \mathrm{ng}$ of total RNA, according to a protocol validated by Dittami et al. [25]. The optimal number of amplification cycles was determined by semiquantitative PCR, and ranged from 20 to 25 for our samples. The PCR products were purified by first vortexing with one volume of phenol:chloroform:isoamyl alcohol (25:24:1), then by precipitating the aqueous phase with 0.5 volumes of $7.5 \mathrm{M} \mathrm{NH}_{4} \mathrm{OH}, 6 \mu \mathrm{g}$ of nuclease-free Glycogen (Ambion, Austin, USA), and 2.4 volumes of ethanol. After centrifugation at RT (20 min at 14,000 g), the pellet was washed with $70 \% \mathrm{EtOH}$, centrifuged (10 $\mathrm{min}$ at 14,000 g and RT) and resuspended in $14 \mu \mathrm{L}$ of $\mathrm{H}_{2} \mathrm{O}$. To finish, cDNAs were run on an agarose gel and quantified with a NanoDrop ND-1000 spectrophotometer, to ensure that they met the requirements for hybridization by Roche NimbleGen (Madison, WI, USA) (concentration $>250 \mu \mathrm{g} \mathrm{L}^{-1}$, $A_{260 / 280} \geq 1.7, \quad A_{260 / 230} \geq 1.5$, median size $\geq 400$ bp). Samples were Cy3-labeled and hybridized to the E. siliculosus EST-based Roche NimbleGen 4-plex expression array [ArrayExpress:A-MEXP-1445], described in [25]. It is based on a set of 90,637 expressed sequence tags, corresponding to 8,165 contigs and 8,874 singletons, although in some cases, several contigs/singletons belonging to the same genomic locus had not been assembled. In total, the 17,039 contigs/singletons cover about 10,600 of the 16,256 predicted unique genes in the E. siliculosus genome [59]. Each of the contigs/singletons is represented by four unique 60-mer probes on the array.

\section{Validation of microarray results using quantitative PCR}

To assess the reliability of fold-change estimations in mRNA abundance by microarray, sixteen genes that exhibited diverse expression patterns in the microarray analysis were analyzed by real time quantitative PCR (RT-qPCR): eight up-regulated, five down-regulated, and three without significant changes (Additional file 10). RT-qPCR was performed as previously described [58], using the three experimental replicates that were also employed in the microarray experiment. Briefly, SYBR green assays were used to determine cDNA copy numbers based on gDNA standard curves ranging from 37 to 48671 copies of the E. siliculosus genome. All primer pairs used are given in Additional file 10. Amplification 
efficiencies were determined for each primer pair and ranged from $90-110 \%$. Furthermore, melting curve analyses were run to confirm that only one product was amplified, and the $\mathrm{mN}$ primer pair targeting an intron was used to verify the absence of any genomic DNA [58]. The geometric mean of two reference genes, EF1 (translation elongation factor 1 alpha) and UBCE (ubiquitin conjugating enzyme) was then used to normalize gene expression. Most tested genes had similar expression profiles in both the microarray and the RT-qPCR experiment. We observed an overall correlation $r^{2}$ of 0.82 between the experiments, indicating good reproducibility (Additional file 10). Different expression patterns between microarray and qPCR were obtained only for two genes coding for a putative zinc/iron permease (ZnFePer) and a tyrosinase-like protein (TYR).

\section{Statistical analysis of microarray experiments}

Normalization and probe averaging of raw microarray data were carried out by Roche Nimblegen using quantile normalization [60], and the robust multichip average algorithm [61]. Normalized microarray signals were then log2-transformed and analysed in a two-way ANOVA with time $(4 \mathrm{~h}, 8 \mathrm{~h})$ and stress $\left(0\right.$ or $250 \mu \mathrm{g} \mathrm{L}{ }^{-1} \mathrm{Cu}$ ) as factors using TIGR MeV 4.4 [62]. In this analysis, the false discovery rate (FDR) was limited to $5 \%$ according to Benjamini and Hochberg [63]. In parallel, a metaanalysis was carried out to compare our data to a previous dataset available for other stressors [25]. Transcripts previously found to be significantly regulated $(\mathrm{p}<0.05$, fold-change compared to control $>2$ ) after either $6 \mathrm{~h}$ [25] or $4 \mathrm{~h}$ or $8 \mathrm{~h}$ (this study) were taken into account, but to reduce the impact of false negatives on this analysis no FDR correction was applied here. The results of the meta-analysis are therefore useful to determine which conditions a gene was regulated in, but not to generate lists of significant genes. Hierarchical clustering of data both from $\mathrm{Cu}$ stress- and previously published oxidative and salt stress experiments [25] was carried out with TigrMEV version 4.8 using the HCL-support tree function (100 bootstrap replicates). For this analysis, log2ratios (stress/control) were calculated for each replicate, and Euclidian distance was used as distance matrix.

\section{Automatic annotation of contigs/singletons}

For the purpose of generating automatic genome annotations, the contigs/singletons used for the microarray design [25] were replaced by the full coding sequence using data from the E. siliculosus genome project [24]. To this end, all contigs/singletons were blasted against the complete data set of predicted mRNAs (https://bioinformatics.psb.ugent.be/gdb/ectocarpus/Archive/Ectsi_mRNA_ Aug2011.tfa.gz). Different thresholds were tested for these blast searches, with e-value cutoffs from $1 \mathrm{e}-20$ to $1 \mathrm{e}-5$, and identity cutoffs from $80 \%$ to $99 \%$. Only identity-cutoffs > $95 \%$ and e-value cutoffs $<1$ e-15 resulted in a reduction of the number of sequences with a blast hit. After manual examination of the blast results in question, an identity-cutoff of $90 \%$ and an e-value cutoff of $1 \mathrm{e}-10$ were chosen for further analyses. If a blast hit was found to match these criteria, the original sequence was replaced by the complete mRNA sequence for annotation purposes. These results were also used to determine the corresponding genomic loci throughout the manuscript. If no corresponding genomic locus was found using this approach, previously generated correspondences available [64] were used, as these allowed for longer UTRs than those predicted in the genome. All sequences presenting differential expression were automatically annotated and classified following a procedure previously described [25]. Briefly, annotation was carried out with KEGG orthology (KO) numbers using the KO-Based Annotation System KOBAS [65] and with Gene Ontology (GO) terms [66] using the GO Term Prediction and Evaluation Tool GOPET [67].

\section{Phylogenetic analysis and protein fold prediction}

Candidate $\mathrm{ABC}$ transporters were identified in the $E$. siliculosus genome based on manual annotations [24] or the presence of the "ABC_tran" PFAM motif, and classified according to Dean et al. [31]. To this end, protein sequences of classified human [31] and A. thaliana [32] $\mathrm{ABC}$ transporters, as well as the candidate E. siliculosus sequences, were aligned to the "ABC_tran" motive with Hmmer3 [68]. The resulting alignment formed the basis for maximum likelihood phylogenetic reconstruction using PhyML 3.0 [69]. Analyses were carried out with the LG substitution model [70], a discrete gamma model, and an estimated proportion of invariable sites of 0.006 , as these parameters were found to best describe the data using ProtTest 2.4 [70]. An approximate likelihood ratio test was used to evaluate the robustness of the best tree and results were plotted using MEGA 5.1 [71]. Protein fold prediction was carried out with the Phyre 2 automatic fold recognition server [72] using the intensive modelling mode [73].

\section{Metabolite profiling and data analysis}

After harvesting, samples were freeze-dried and ground in a mortar. For each sample, $250 \mathrm{ng}$ of 12-OH-lauric acid was added as an internal standard. Extraction was carried out from $300 \mathrm{mg}$ (fresh weight) of algal material during $1 \mathrm{~h}$ at $4^{\circ} \mathrm{C}$ with $1 \mathrm{ml} \mathrm{MeOH}: \mathrm{H}_{2} \mathrm{O}$ (8:2) Samples were then centrifuged at $1,500 \mathrm{~g}$ for $15 \mathrm{~min}$ at $4^{\circ} \mathrm{C}$. Aliquots of the supernatants were then used for metabolomic analysis by ultra-high pressure liquid chromatography coupled to mass spectrometry analysis (UPLC-MS), and for gas chromatography coupled to mass spectrometry (GC-MS) profiling. 
UPLC was performed using an RSLC Ultimate 3000 from Dionex equipped with a quaternary pump and autosampler. Separations were achieved using an Acclaim RSLC $120 \mathrm{C} 181.9 \mu \mathrm{m}(2.1 \times 100 \mathrm{~mm})$ column (Dionex; Thermo Fisher Scientific, Courtaboeuf, France) maintained at $20^{\circ} \mathrm{C}$ using $5 \mu \mathrm{L}$ injection volume and a flow-rate of $250 \mu \mathrm{L} \mathrm{min}{ }^{-1}$. Mobile phase A was composed of $0.1 \%$ acetic acid in $\mathrm{H}_{2} \mathrm{O}$, and mobile phase $\mathrm{B}$ was $0.1 \%$ acetic acid in acetonitrile. The gradient consisted of an initial hold at $20 \%$ mobile phase B for 2 min, followed by a linear gradient to $100 \%$ B in 8 min and a hold for $14 \mathrm{~min}$, followed by re-equilibration for $6 \mathrm{~min}$ at $20 \% \mathrm{~B}$, for a total run time of $30 \mathrm{~min}$. Mass spectrometry was performed on a Thermo Scientific LTQ-Orbitrap Discovery ${ }^{\mathrm{TM}}$ mass spectrometer. Scans were collected in both positive and negative ESI mode over a range of $\mathrm{m} / \mathrm{z} 50-1000$. Ionization parameters were set as follows: sheath gas 5 psi, auxiliary gas 5 (arbitrary units), sweep gas 0 (arbitrary units), spray voltage $2.7 \mathrm{kV}$, capillary temperature $300^{\circ} \mathrm{C}$, capillary voltage $60 \mathrm{~V}$, tube lens voltage $127 \mathrm{~V}$ and heater temperature $300^{\circ} \mathrm{C}$. The Xcalibur 2.1 software was used for instrument control and data acquisition. Raw files were converted to the mzXML format using MassMatrix File Conversion Tools (Version 3.9, April 2011). Data were processed by XCMS [74] running under $\mathrm{R}$ or on the online version, using the parameters listed in Additional file 11, and further annotated by CAMERA [75]. This approach allowed detecting 392 monoisotopic peaks, among which 31 free fatty acids and oxylipins were further identified by comparison with standards and mass spectral databases Metlin, HMDB and MassBank.

GC-MS was used for profiling of amino acids. To this end, $100 \mu \mathrm{L}$ aliquots of the $\mathrm{MeOH}: \mathrm{H}_{2} \mathrm{O}(8: 2)$ fraction were evaporated under a stream of nitrogen and resuspended in $60 \mu \mathrm{L}$ of $20 \mathrm{~g} \mathrm{~L}^{-1}$ methoxyamine-hydrochloride (SigmaAldrich, Saint-Quentin Fallavier, France) in pyridine before incubation at $60^{\circ} \mathrm{C}$ for $1 \mathrm{~h}$. After addition of $50 \mu \mathrm{L}$ of N,O-bis(trimethylsisyl)trifluoroacetamide, samples were incubated $1 \mathrm{~h}$ at $40^{\circ} \mathrm{C}$ and then at room temperature overnight before injection. Derivatized metabolites were analyzed by GC-MS using an Agilent GC 6890+ coupled to a 5975 MS Detector (Agilent, Les Ulis, France) and equipped with a DB-5MS column $(30 \mathrm{~m} \times 0.25 \mathrm{~mm}$ I.D. $\times$ $0.25 \mu \mathrm{m}$ film thickness; J\&W Scientific, Agilent) in the EI mode at $70 \mathrm{eV}$. The temperature gradient used was $60^{\circ} \mathrm{C}$ for $5 \mathrm{~min}, 60-120^{\circ} \mathrm{C}$ at $30^{\circ} \mathrm{C} \mathrm{min}^{-1}, 120-290^{\circ} \mathrm{C}$ at $4^{\circ} \mathrm{C} \mathrm{min}^{-1}$, and $290^{\circ} \mathrm{C}$ for $10 \mathrm{~min}$. Sixteen amino acids were identified by comparison with standards.

By combining the data obtained in both positive and negative ion mode by UPLC-MS and by GC-MS, 47 metabolites corresponding to fatty acids, oxylipins, and amino acids could be reliably identified. Multivariate statistical analyses of metabolite data were carried out using SIMCA-P (12.0.1, Umetrics, Umeå, Sweden). Data were $\log 10$-transformed and normalized using Pareto scaling. Partial least squares discriminant analysis (PLS-DA) was carried out on the 392 monoisotopic peaks detected by the UPLC-MS analysis, and also independently on free fatty acids and on the amino acids. Hierarchical clustering analysis of the 392 peaks was carried out with TigrMeV as described for gene expression data, except that metabolite quantities were normalized by dividing all values by the highest value obtained in any of the conditions tested (all normalized values ranged from 0 to 1 ) instead of calculating log2-ratios. A similar analysis was also performed for the 47 identified metabolites, and their relative quantities were further analysed using a two-way ANOVA in analogy to the gene expression data (see above).

\section{Availability of supporting data}

Microarray data have been deposited in the ArrayExpress database [76] under the accession number E-MTAB-1286. The Blast2GO database generated for this array is available at the Ectocarpus Transcriptomics Homepage [64].

\section{Additional files}

\begin{abstract}
Additional file 1: List of the 627 contigs/singletons found to be differentially regulated under $\mathrm{Cu}$ treatments at an FDR of $5 \%$. Sequences were manually grouped into functional categories. Values highlighted in yellow correspond to genes up-regulated, while blue background indicates genes down-regulated.
\end{abstract}

Additional file 2: Venn diagram representing the number of significantly up-regulated (a) and down-regulated (b) contigs/singletons under copper (Cu), oxidative, hypersaline (Hyper), and hyposaline (Hypo) stress conditions ( $p<0.05$ ).

Additional file 3 : List of contigs/singletons identified as differentially regulated ( $p<0.05$; fold-change $>2$; no FDR correction) under different abiotic stress conditions tested through the meta-analysis. Protein definitions were retrieved from the E. siliculosus genome database in March 2013

Additional file 4: Hierarchical clustering of gene expression data obtained by microarray in E. siliculosus submitted to different abiotic stress conditions. Hypo_1-4 = hyposaline stress (salinity of 4 ppt, 6 h), Hyper_1-4 = hypersaline stress (salinity of 96 ppt, 6 h), Oxi_1-4 = oxidative stress (10 $\mathrm{mM} \mathrm{H}_{2} \mathrm{O}_{2}, 6$ h; see Dittami et al. [25] for experimental details for these stressors), and Cu_1_4h - Cu_3_8h (250 $\mu \mathrm{g} \mathrm{L}^{-1}$ copper stress, 4-8 h; this study). The heat map shows log2-ratios of gene expression in stress compared to control conditions. Gene trees and sample trees were obtained by hierarchical clustering and

"Euclidean distance" as metric

Additional file 5: (A) ClustalW multiple alignment of the CYP74 family IHCD domains from Esi0060_0078 and homologs. The conserved catalytic residues FXXXFXSXX were highlighted in red for the CYP74A conserved phenylalanine residues and blue for the AOS specific serine residue. (B) Ribbon diagram of a predicted structural model of Esi0060_0078 prepared with the Phyre2 software [73]

Additional file 6: Summary of features observed in the putative E. siliculosus $\mathrm{Cu}$ induced heavy metal $\mathrm{P}_{1 \mathrm{~B}}$-ATPase (Esi0023_0054). This sequence contains conserved heavy metal-associated (HMA), E1-E2 ATPase superfamily and haloacid dehalogenase (HAD) domains. The diagram was obtained by amino acid sequence analysis based on the Conserved Domains and Protein Classification Database. 
Additional file 7: Results of partial least squares discriminant analysis (PLS-DA) carried out for the compounds detected in the Cu-stress experiment. The plot represents the variations of 392 monoisotopic peaks quantified by UPLC-MS in positive ion mode in algal samples harvested after $4 \mathrm{~h}$ and $8 \mathrm{~h}$ of $\mathrm{Cu}$-stress (red and yellow spots, respectively), as well as the corresponding controls (green and blue spots).

Additional file 8: Hierarchical clustering of 392 monoisotopic peaks quantified by UPLC-MS in positive and negative ion mode in algal samples under copper stress and control conditions. Concentrations of each metabolite were normalized to a maximum of 1 (see Methods) and clustering was carried out with the Euclidean distance matrix.

Additional file 9: Results of PLS-DA representing the variations of (A) amino acid (GC-MS analysis) and (B) fatty acid contents (UPLC-MS analysis) between control and $\mathrm{Cu}$ treated samples.

Additional file 10: Primers used for qPCR experiments, and comparison of results obtained by microarray and qPCR analysis for selected genes. In the included graph, each point represents the Log2-ratio of the mRNA abundance determined by microarray in copper stress and in control conditions for a specific gene after $4 \mathrm{~h}$ or $8 \mathrm{~h}$ of $\mathrm{Cu}$ treatment (mean of three biological replicates) plotted against the same ratio determined by GPCR

Additional file 11: Parameters used for XCMS analysis.

\section{Competing interests}

The authors declare that they have no competing interests.

\section{Authors' contributions}

AR, SD, SG, JC, CB, PP, and TT conceived the study; AR and SG carried out the experiments; $A R, S D, S G$, and $T$ analyzed the data and wrote the manuscript; all authors corrected and approved the final manuscript.

\section{Acknowledgments}

We are especially grateful to Laurence Dartevelle for valuable help with Ectocarpus siliculosus cultivation. This work has been partially funded by Marine Genomics Europe NoE 7 (EU contract n GOCE-CT-2004-505403), and the French Embassy and the CONICYT of Chile through PhD fellowship to A.R. This work was also supported by the Laboratoire International Associé 'Dispersal and Adaptation of Marine Species' (LIA DIAMS) PUC, Chile, and CNRS-UPMC, France. S.G. benefited from the support of the French Government via the National Research Agency through the investment expenditure program IDEALG (ANR-10-BTBR-04). Additional support came from FONDAP 1501-0001 (Program 7) to J.A.C. and A.R.

\section{Author details}

'UPMC Univ Paris 06, UMR 8227, Integrative Biology of Marine Models, Station Biologique de Roscoff, Sorbonne Universités, CS 90074, F-29688 Roscoff cedex, France. ${ }^{2}$ CNRS, UMR 8227, Integrative Biology of Marine Models, Station Biologique de Roscoff, CS 90074, F-29688 Roscoff cedex, France. ${ }^{3}$ Departamento de Ecología, Center of Applied Ecology \& Sustainability, Facultad de Ciencias Biológicas, Pontificia Universidad Católica de Chile, Santiago, Chile. ${ }^{4}$ Plate-forme MetaboMER, CNRS \& UPMC, FR2424, Station Biologique, 29680 Roscoff, France. ${ }^{5}$ Present addresses: Department of Plant Systems Biology, VIB and Department of Plant Biotechnology and Bioinformatics, Ghent University, Technologiepark 927, Ghent B-9052, Belgium.

Received: 20 December 2013 Accepted: 22 April 2014 Published: 1 May 2014

\section{References}

1. Cock JM, Peters AF, Coelho SM: Brown algae. Curr Biol 2011, 21:R573-R575.

2. Correa JA, Castilla J, Ramirez M, Varas M, Lagos N, Vergara S, Moenne A, Roman D, Brown MT: Copper, copper mine tailings and their effect on the marine algae in Northern Chile. J Appl Phycol 1999, 11:57-67.

3. Gledhill M, Nimmo M, Hill SJ, Brown MT: The toxicity of copper (II) species to marine algae, with particular reference to macroalgae. J Phycol 1997, 33:2-11.
4. Livingstone DR: Contaminant-stimulated reactive oxygen species production and oxidative damage in aquatic organisms. Mar Pollut Bull 2001, 42:656-666.

5. Puig S, Andres-Colas N, Garcia-Molina A, Penarrubia L: Copper and iron homeostasis in Arabidopsis: responses to metal deficiencies, interactions and biotechnological applications. Plant Cell Environ 2007, 30:271-290.

6. Halliwell B, Gutteridge JMC: Biologically relevant metal ion-dependent hydroxyl radical generation An update. FEBS Lett 1992, 307:108-112.

7. Fernandes JC, Henriques FS: Biochemical, physiological, and structural effects of excess copper in plants. Bot Rev 1991, 57:246-273.

8. Maksymiec W: Effect of copper on cellular processes in higher plants. Photosynthetica 1997, 34:321-342

9. Yruela I, Pueyo JJ, Alonso PJ, Picorel R: Photoinhibition of photosystem II from higher plants. ffect of copper inhibition. J Biol Chem 1996, 271:27408-27415.

10. Chmielowska-Bąk J, Deckert J: A common response to common danger? Comparison of animal and plant signaling pathways involved in cadmium sensing. J Cell Commun Signal 2012, 6:191-204.

11. Hall JL: Cellular mechanisms for heavy metal detoxification and tolerance. J Exp Bot 2002, 53:1-11.

12. Andrés-Colás N, Sancenón V, Rodríguez-Navarro S, Mayo S, Thiele DJ, Ecker JR, Puig S, Peñarrubia L: The Arabidopsis heavy metal P-type ATPase HMA5 interacts with metallochaperones and functions in copper detoxification of roots. Plant J 2006, 45:225-236.

13. Wanke $D$, Kolukisaoglu HU: An update on the $A B C C$ transporter family in plants: many genes, many proteins, but how many functions? Plant Biol 2010, 12:15-25.

14. Küpper H, Setlik I, Spiller M, Kupper FC, Prasil O: Heavy metal-induced inhibition of photosynthesis: targets of in vivo heavy metal chlorophyll formation. J Phycol 2002, 38:429-441.

15. Nielsen HD, Nielsen SL: Adaptation to high light irradiances enhances the photosynthetic $\mathrm{Cu}^{2+}$ resistance in $\mathrm{Cu}^{2+}$ tolerant and non-tolerant populations of the brown macroalgae Fucus serratus. Mar Pollut Bull 2010, 60:710-717

16. Contreras L, Moenne A, Correa JA: Antioxidant responses in Scytosiphon lomentaria (Phaeophyceae) inhabiting copper-enriched coastal environments. J Phycol 2005, 41:1184-1195.

17. Dring MJ: Stress resistance and disease resistance in seaweeds: the role of reactive oxygen metabolism. Adv Bot Res 2006, 43:175-207.

18. Morris CA, Nicolaus B, Sampson V, Harwood JL, Kille P: Identification and characterization of a recombinant metallothionein protein from a marine alga, Fucus vesiculosus. Biochem J 1999, 338(Pt 2):553-560.

19. Pawlik-Skowronska B, Pirszel J, Brown MT: Concentrations of phytochelatins and glutathione found in natural assemblages of seaweeds depend on species and metal concentrations of the habitat. Aquat Toxicol 2007, 83:190-199.

20. Contreras L, Moenne A, Gaillard F, Potin P, Correa JA: Proteomic analysis and identification of copper stress-regulated proteins in the marine alga Scytosiphon gracilis (Phaeophyceae). Aquat Toxicol 2010, 96:85-89.

21. Ritter A, Ubertini M, Romac S, Gaillard F, Delage L, Mann A, Cock JM, Tonon T, Correa JA, Potin P: Copper stress proteomics highlights local adaptation of two strains of the model brown alga Ectocarpus siliculosus. Proteomics 2010, 10:2074-2088.

22. Ritter A, Goulitquer S, Salaün J-P, Tonon T, Correa JA, Potin P: Copper stress induces biosynthesis of octadecanoid and eicosanoid oxygenated derivatives in the brown algal kelp Laminaria digitata. New Phytol 2008, 180:809-821.

23. Charrier B, Coelho SM, Le Bail A, Tonon T, Michel G, Potin P, Kloareg B, Boyen C, Peters AF, Cock JM: Development and physiology of the brown alga Ectocarpus siliculosus: two centuries of research. New Phytol 2008, 177:319-332

24. Cock JM, Sterck L, Rouze P, Scornet D, Allen AE, Amoutzias G, Anthouard V, Artiguenave F, Aury JM, Badger JH, Beszteri B, Billiau K, Bonnet E, Bothwell JH, Bowler C, Boyen C, Brownlee C, Carrano CJ, Charrier B, Cho GY, Coelho SM, Collén J, Corre E, Da Silva C, Delage L, Delaroque N, Dittami SM, Doulbeau S, Elias M, Farnham G, et al: The Ectocarpus genome and the independent evolution of multicellularity in brown algae. Nature 2010, 465:617-621.

25. Dittami SM, Scornet D, Petit J-L, Segurens B, Da Silva C, Corre E, Dondrup M, Glatting K-H, Konig R, Sterck L, Rouzé P, Van de Peer Y, Cock JM, Boyen C, Tonon T: Global expression analysis of the brown alga Ectocarpus siliculosus (Phaeophyceae) reveals large-scale reprogramming of the transcriptome in response to abiotic stress. Genome Biol 2009, 10:R66. 
26. Dittami SM, Gravot A, Renault D, Goulitquer S, Eggert A, Bouchereau A Boyen $C$, Tonon $T$ : Integrative analysis of metabolite and transcript abundance during the short-term response to saline and oxidative stress in the brown alga Ectocarpus siliculosus. Plant Cell Environ 2011, 34:629-642.

27. Medina M, Andrade S, Faugeron S, Lagos N, Mella D, Correa JA: Biodiversity of rocky intertidal benthic communities associated with copper mine tailing discharges in northern Chile. Mar Pollut Bull 2005, 50:396-409.

28. Russel G, Morris OP: Copper tolerance in marine fouling alga Ectocarpus siliculosus. Nature 1970, 228:288-289.

29. Rayko E, Maumus F, Maheswari U, Jabbari K, Bowler C: Transcription factor families inferred from genome sequences of photosynthetic stramenopiles. New Phytol 2010, 188:52-66.

30. Schauser L, Roussis A, Stiller J, Stougaard J: A plant regulator controlling development of symbiotic root nodules. Nature 1999, 402:191-195.

31. Dean M, Rzhetsky A, Allikmets R: The human ATP-binding cassette (ABC) transporter superfamily. Genome Res 2001, 11:1156-1166.

32. Verrier PJ, Bird D, Burla B, Dassa E, Forestier C, Geisler M, Klein M, Kolukisaoglu Ü, Lee Y, Martinoia E, Murphy A, Rea PA, Samuels L, Schulz B, Spalding EJ, Yazaki K, Theodoulou FL: Plant ABC proteins - a unified nomenclature and updated inventory. Trends Plant Sci 2008, 13:151-159.

33. Dittami S, Michel G, Collen J, Boyen C, Tonon T: Chlorophyll-binding proteins revisited - a multigenic family of light-harvesting and stress proteins from a brown algal perspective. BMC Evol Biol 2010, 10:365.

34. Gravot A, Dittami SM, Rousvoal S, Lugan R, Eggert A, Collen J, Boyen C, Bouchereau A, Tonon T: Diurnal oscillations of metabolite abundances and gene analysis provide new insights into central metabolic processes of the brown alga Ectocarpus siliculosus. New Phytol 2010, 188:98-110

35. Noctor $\mathrm{G}$, Foyer $\mathrm{CH}$ : A re-evaluation of the ATP:NADPH budget during $\mathrm{C} 3$ photosynthesis: a contribution from nitrate assimilation and its associated respiratory activity? J Exp Bot 1998, 49:1895-1908.

36. Foyer $\mathrm{CH}$, Bloom AJ, Queval G, Noctor G: Photorespiratory metabolism: genes, mutants, energetics, and redox signaling. Annu Rev Plant Biol 2009, 60:455-484

37. Belknap WR, Garbarino JE: The role of ubiquitin in plant senescence and stress responses. Trends Plant Sci 1996, 1:331-335.

38. Hockin NL, Mock T, Mulholland F, Kopriva S, Malin G: The response of diatom central carbon metabolism to nitrogen starvation is different from that of green algae and higher plants. Plant Physiol 2012, 158:299-312.

39. Miller R, Wu G, Deshpande RR, Vieler A, Gärtner K, Li X, Moellering ER, Zäuner S, Cornish AJ, Liu B, Bullard B, Sears BB, Kuo MH, Hegg EL, Shachar-Hill Y, Shiu SH, Benning C: Changes in transcript abundance in Chlamydomonas reinhardtii following nitrogen deprivation predict diversion of metabolism. Plant Physiol 2010, 154:1737-1752.

40. Gillaspy GE: The cellular language of myo-inositol signaling. New Phytol 2011, 192:823-839.

41. Chaouch S, Noctor G: Myo-inositol abolishes salicylic acid-dependent cell death and pathogen defence responses triggered by peroxisomal hydrogen peroxide. New Phytol 2010, 188:711-718.

42. Meng PH, Raynaud C, Tcherkez G, Blanchet S, Massoud K, Domenichini S, Henry Y, Soubigou-Taconnat L, Lelarge-Trouverie C, Saindrenan P: Crosstalks between myo-inositol metabolism, programmed cell death and basal immunity in Arabidopsis. Plos One 2009, 4:e7364.

43. Donahue JL, Alford SR, Torabinejad J, Kerwin RE, Nourbakhsh A, Ray WK, Hernick M, Huang X, Lyons BM, Hein PP, Gillaspy GE: The Arabidopsis thaliana myo-inositol 1-phosphate synthase1 gene is required for myo-inositol synthesis and suppression of cell death. Plant Cell 2010, 22:888-903.

44. Dalisay DS, Webb JS, Scheffel A, Svenson C, James S, Holmstrom C, Egan S, Kjelleberg S: A mannose-sensitive haemagglutinin (MSHA)-like pilus promotes attachment of Pseudoalteromonas tunicata cells to the surface of the green alga Ulva australis. Microbiol 2006, 152:2875-2883.

45. Arnold TM, Targett NM, Tanner CE, Hatch WI, Ferrari KE: Evidence for methyl jasmonate-induced phlorotannin production in Fucus vesiculosus (Phaeophyceae). J Phycol 2001, 37:1026-1029.

46. de Franco P-O, Rousvoal S, Tonon T, Boyen C: Whole genome survey of the glutathione transferase family in the brown algal model Ectocarpus siliculosus. Mar Genom 2009, 1:135-148.

47. Küpper FC, Gaquerel E, Cosse A, Adas F, Peters AF, Müller DG, Kloareg B, Salaün J-P, Potin P: Free fatty acids and methyl jasmonate trigger defense reactions in Laminaria digitata. Plant Cell Physiol 2009, 50:789-800.
48. Kazan K, Manners JM: Jasmonate signaling: toward an integrated view. Plant Physiol 2008, 146:1459-1468.

49. Farmer EE, Davoine C: Reactive electrophile species. Curr Opin Plant Biol 2007, 10:380-386

50. Mueller S, Hilbert B, Dueckershoff K, Roitsch T, Krischke M, Mueller MJ, Berger S: General detoxification and stress responses are mediated by oxidized lipids through TGA transcription factors in Arabidopsis. Plant Cell 2008, 20:768-785.

51. Stotz HU, Mueller S, Zoeller M, Mueller MJ, Berger S: TGA transcription factors and jasmonate-independent COI1 signalling regulate specific plant responses to reactive oxylipins. J Exp Bot 2013, 64:963-975.

52. Blaby-Haas CE, Merchant SS: The ins and outs of algal metal transport. Biochim Biophys Acta 1823, 2012:1531-1552.

53. Wenzel JJ, Piehler A, Kaminski WE: ABC A-subclass proteins: gatekeepers of cellular phospho- and sphingolipid transport. Front Biosci 2007, 12:16.

54. Kim S, Yamaoka Y, Ono H, Kim H, Shim D, Maeshima M, Martinoia E, Cahoon EB, Nishida I, Lee Y: AtABCA9 transporter supplies fatty acids for lipid synthesis to the endoplasmic reticulum. Proc Natl Acad Sci 2013, 110:773-778.

55. Yokosho K, Yamaji N, Ma JF: An Al-inducible MATE gene is involved in external detoxification of $\mathrm{Al}$ in rice. Plant J 2011, 68:1061-1069.

56. Tonon T, Eveillard D, Prigent S, Bourdon J, Potin P, Boyen C, Siegel A: Toward systems biology in brown algae to explore acclimation and adaptation to the shore environment. OMICS 2011, 15:883-892.

57. Apt KE, Clendennen SK, Powers DA, Grossman AR: The gene family encoding the fucoxanthin chlorophyll proteins from the brown alga Macrocystis pyrifera. Mol Gen Genet 1995, 246:455-464.

58. Le Bail A, Dittami S, de Franco P-O, Rousvoal S, Cock M, Tonon T, Charrier B: Normalisation genes for expression analyses in the brown alga model Ectocarpus siliculosus. BMC Mol Biol 2008, 9:75.

59. Dittami SM, Proux C, Rousvoal S, Peters AF, Cock JM, Coppee J-Y, Boyen C, Tonon T: Microarray estimation of genomic inter-strain variability in the genus Ectocarpus (Phaeophyceae). BMC Mol Biol 2011, 12:2.

60. Bolstad BM, Irizarry RA, Astrand M, Speed TP: A comparison of normalization methods for high density oligonucleotide array data based on variance and bias. Bioinformatics 2003, 19:185-193.

61. Irizarry RA, Hobbs B, Collin F, Beazer-Barclay YD, Antonellis KJ, Scherf U, Speed TP: Exploration, normalization, and summaries of high density oligonucleotide array probe level data. Biostatistics 2003, 4:249-264.

62. Saeed A, Sharov V, White J, Li J, Liang W, Bhagabati N, Braisted J, Klapa M, Currier T, Thiagarajan M, Sturn A, Snuffin M, Rezantsev A, Popov D, Ryltsov A, Kostukovich E, Borisovsky I, Liu Z, Vinsavich A, Trush V, Quackenbush J: TM4: a free, open-source system for microarray data management and analysis. Biotechniques 2003, 34:374-377.

63. Benjamini $Y$, Hochberg $Y$ : Controlling the false discovery rate - a practical and powerful approach to multiple testing. J Roy Stat Soc B Met 1995, 57:289-300.

64. The Ectocarpus transcriptomics homepage. [http://www.sb-roscoff.fr/ UMR7139/ectocarpus/transcriptomics/annotations.html]

65. Wu CH, Apweiler R, Bairoch A, Natale DA, Barker WC, Boeckmann B, Ferro S, Gasteiger E, Huang HZ, Lopez R, Magrane M, Martin MJ, Mazumder R, O'Donovan C, Redaschi N, Suzek B: The Universal Protein Resource (UniProt): an expanding universe of protein information. Nucleic Acids Res 2006, 34:D187-D191.

66. Ashburner M, Ball CA, Blake JA, Botstein D, Butler H, Cherry JM, Davis AP, Dolinski K, Dwight SS, Eppig JT, Harris MA, Hill DP, Issel-Tarver L, Kasarskis A, Lewis S, Matese JC, Richardson JE, Ringwald M, Rubin GM, Sherlock G: Gene ontology: tool for the unification of biology. Nat Genet 2000, 25:25-29.

67. Vinayagam A, del Val C, Schubert F, Eils R, Glatting K-H, Suhai S, Konig R: GOPET: a tool for automated predictions of gene ontology terms. BMC Bioinformatics 2006, 7:161.

68. Eddy SR: Accelerated profile HMM searches. PLoS Comput Biol 2011, 7:e1002195

69. Guindon S, Gascuel O: A simple, fast, and accurate algorithm to estimate large phylogenies by maximum likelihood. Syst Biol 2003, 52:696-704.

70. Abascal F, Zardoya R, Posada D: ProtTest: selection of best-fit models of protein evolution. Bioinformatics 2005, 21:2104-2105.

71. Tamura K, Peterson D, Peterson N, Stecher G, Nei M, Kumar S: MEGA5: molecular evolutionary genetics analysis using maximum likelihood, evolutionary distance, and maximum parsimony methods. Mol Biol Evol 2011, 28:2731-2739. 
72. The protein homology/analogy recognition engine $\mathrm{V} 2.0$. [http://www.sbg.bio.ic.ac.uk/phyre2/]

73. Kelley LA, Sternberg MJE: Protein structure prediction on the Web: a case study using the Phyre server. Nat Protoc 2009, 4:363-371.

74. Smith CA, Want EJ, O'Maille G, Abagyan R, Siuzdak G: XCMS: processing mass spectrometry data for metabolite profiling using Nonlinear peak alignment, matching, and identification. Anal Chem 2006, 78:779-787.

75. Kuhl CTR, Böttcher C, Larson TR, Neumann S: CAMERA: an integrated strategy for compound spectra extraction and annotation of liquid chromatography/mass spectrometry data sets. Anal Chem 2012, 84:283-299.

76. The ArrayExpress database. [http://www.ebi.ac.uk/arrayexpress]

doi:10.1186/1471-2229-14-116

Cite this article as: Ritter et al:: Transcriptomic and metabolomic analysis of copper stress acclimation in Ectocarpus siliculosus highlights signaling and tolerance mechanisms in brown algae. BMC Plant Biology 2014 14:116.

\section{Submit your next manuscript to BioMed Central and take full advantage of:}

- Convenient online submission

- Thorough peer review

- No space constraints or color figure charges

- Immediate publication on acceptance

- Inclusion in PubMed, CAS, Scopus and Google Scholar

- Research which is freely available for redistribution 